\title{
Shear Properties of the Strain Hardening Cementitious Composite Material
}

\author{
Hadi Baghi ${ }^{1}$, Joaquim A.O.Barros ${ }^{2}$
}

\begin{abstract}
Recently, Strain Hardening Cementitious Composite (SHCC) material has been used for the shear strengthening and the structural rehabilitation of reinforced concrete structures. However, the shear behavior of this material has not been yet fully understood due to lack of an appropriate and accurate direct shear test method. This paper aims to investigate the shear properties of the SHCC material. For this purpose, Iosipescu shear test was selected, where loads are applied in antisymmetric four points bending, assuring a pure shear section at the center of the specimen. A special geometry for the specimen was adopted in order to assure a uniform shear stress distribution in the pure shear section. This experimental test can characterize the shear behavior of SHCC material.

The experimental test was simulated by the FEM-based computer program, FEMIX. To predict the average shear stress-sliding response, the shear crack softening diagram, available in the multi-directional fixed smeared crack model, was used. After demonstration the good predictive performance of the numerical model, a parametric study was carried out to evaluate the influence of shear retention factor, fracture energy of mode II, and crack shear strength on the average shear stress-sliding response of the SHCC. The advantage of SHCC instead of conventional mortar was also studied.
\end{abstract}

Keywords: Shear; Strain Hardening Cementitious Composite; Iosipescu; Numerical simulation; FEM analysis; Shear retention factor; Shear softening diagram.

\footnotetext{
${ }^{1} \mathrm{PhD}$, ISISE, Department of Civil Engineering, University of Minho, Guimarães, Portugal, (corresponding author) e-mail: hadibaghi@gmail.com.

${ }^{2}$ Full Professor, ISISE, Department of Civil Engineering, University of Minho, Guimarães, Portugal, e-mail: barros@ civil.uminho.pt.
} 


\section{Introduction:}

Strain Hardening Cementitious Composite (SHCC) is a class of fiber reinforced cement composites (FRCC) that exhibits ductile behavior under tensile load, with a strain hardening response rather than the tension softening character presented by conventional FRCC after crack initiation. In SHCC materials, the fiber bridging mechanisms developed during the crack opening process allow a gradual increase of tensile capacity from crack initiation up to a relatively high tensile strain (more than $1 \%$ ), where a failure macro-crack occurs, followed by a strain-softening stage (Baghi et al. 2015, Gideon and Zij1 2007). The tensile strain hardening phase is accompanied by the formation of a diffuse crack pattern of very small crack width. In recent years, SHCC has been used for developing new construction systems and for the structural rehabilitation because this material exhibits ductile shear behavior, high energy absorption capacity, and stable hysteretic loops at large drifts (Parra-Montesinos and Wight 2000; Baghi 2015; Esmaeeli et al. 2015). Hybrid Composite Plate (HCP) has been used to increase the shear capacity of reinforced concrete beams. HCP is a thin plate of SHCC that is strengthened by carbon fiber reinforced polymer (CFRP) laminates. Due to the excellent bond conditions between SHCC plate and CFRP laminates, these reinforcements provide the necessary tensile strength capacity to the HCP. Moreover, the high post-cracking tensile deformability and resistance of SHCC avoid the occurrence of premature fracture failure of this cement composite during the stress transfer process between these two materials, when the HCP is crossed by a shear crack (Baghi et al. 2015; Baghi 2015). However, the shear behavior of SHCC material has not been fully assessed due to the lack of an accurate and appropriate direct shear test method. The great difficulty is to develop an accurate test setup capable of introducing a pure shear stress field. Several shear test setup configurations have been proposed by various researchers in an attempt of capturing the shear behavior of materials (Ohno 1957; Iosipescu 1967; Banks-Sills and Arcan 1983; Reinhardt et al. 1997; Boulifa et al. 2013). Iosipescu shear test was proposed by Iosipescu (1967) for determining the shear properties of metal and welded joints. This test method was considered appropriate for composite materials, and it was adopted by ASTM standard D-5379 (1993). The Iosipescu specimens are loaded in antisymmetric four points bending with a double notch in a region with high shear force and zero bending moment, which can constitute a pure shear section. As shown in Fig. 1, the specimen consists of a depth between two notch roots $\left(h_{0}\right)$, angle of notch root $(\alpha)$, and notch radius $(r)$. This geometry of the specimen can assure a uniform shear stress distribution in the notched plane. 
In the present work, the shear behavior of a developed SHCC was investigated by executing Iosipescu shear tests. For this purpose, an experimental program of the Iosipescu shear test was carried out, composed by 10 specimens. The experimental program is detailed and the obtained results are presented and discussed.

Advanced numerical simulation was carried out by using a multi-directional fixed smeared crack model available in the FEMIX computer program that includes a crack shear softening law to simulate the crack shear stress transfer degradation with the crack widening (Sena-Cruz et al. 2007). After have been demonstrated that the adopted model is capable of fitting with good accuracy the average shear stress-sliding relationship and the crack pattern, a parametric study was carried out to study the influence of the parameters that define the crack shear softening diagram on the shear stress-sliding response of SHCC specimen submitted to direct shear test. The advantage of using SHCC instead of conventional mortar was also analyzed in this parametric study.

\section{Review of Mode II Testing Methods:}

Pure shear panel test method has been developed to measure the relationship between principal stresses and corresponding principal strains (Collins and Mitchell 1991) (Fig. 2a). However, the required facility is highly complicated and the shear stress in the specimen is not uniform (Shang and Zijl 2007).

Double edge notched compression test has been proposed for materials made by high compressive strength $\left(f_{c}^{\prime}=85\right.$

MPa and $f_{t}=5 \mathrm{MPa}$ ), because the results of this test on high strength concrete agreed with the theoretical prediction (Reinhardt et al. 1997). As shown in Fig. 2b, one side of the specimen is loaded in compression and the other side is free. Shortly after mode II crack initiation at the tip of the notch, concrete failed in compression. Hence, this technique is not able to measure fracture energy mode II.

Short beam shear test is one of the simplest tests (Fig. 2c), and is widely used for composites materials (ASTM 2000). However, the short beam shear test cannot give acceptable results due to non-uniform shear stress distribution, and the presence of normal flexural stress.

Ohno shear beam test has been developed to create a pure shear zone (Ohno 1957). The concept of the Ohno shear beam test is presented in Fig. 3a. Based on the shear force (Fig. 3b) and bending moment diagrams (Fig. 3c), a state of pure shear exists at the center of the beam where the bending moment is zero. Bending moment varies along the beam with the maximum ( p.a/2) and the minimum values (0) at the two inner loading points (Fig. 3c). Hence, the failure of the specimen becomes uncertain. Shear failure, flexural failure or a combination of shear and flexural failure 
may occur during this test (Shang and Zijl 2007). In an improvement on the Ohno shear test, a notched specimen has been proposed by Iosipescu (1967), whereby a uniform shear stress distribution in the zero bending moment is possible to assure.

\section{Iosipescu Shear Test:}

This test method is recommended by the ASTM D-5379 (1993) standard for the composite materials. It has been also used for characterizing the shear behavior of fiber reinforced polymer (FRP) (Morton et al. 1992; Odegrad and Kumosa 2000) and wood (Xavier et al. 2004). As shown in the Fig. 4, the concept and mechanism of the Iosipescu shear test is similar to Ohno shear beam test. However, the Iosipescu specimen has a double V-edge notched region of an angle $(\alpha)$, with the minimum height $\left(h_{0}\right)$ at the section of null bending moment. This section is also characterized by a tip radius $(r)$ at the center, whose values are defined in an attempt of assuring a uniform shear stress distribution in this section. Based on the Fig. 4, the center section of the specimen, where the bending moment is zero, is theoretically subjected to pure shear.

A notable amount of experimental research and numerical analysis have been performed either with a single notch (Fig. 5) or double notch (Fig. 4) (Swartz et al. 1987; Ballatore et al. 1990; Barr and Derradj 1990; Ho et al. 1993; Derradj and Kaci 2008). The results of the single notch specimens have shown that cracks initiate in mode II, however it quickly change to a mixed mode. Furthermore, finite element simulations have shown the mode I is the dominant crack propagation mode in this test, therefore single notched specimen is not suitable for the determination of mode II fracture parameters (Swartz et al. 1987).

Krishnan and $\mathrm{Xu}$ (2009) performed a numerical study to measure the variation of the shear stress along the center cross section of the Iosipescu and Ohno specimens. Both specimens had the same sectional area at the pure shear section, for this purpose the thickness of the specimens were different. As shown in Fig. 6, the variation of the shear stress for Ohno specimen is parabolic, while in Iosipescu specimen is almost constant. The geometry of Iosipescu shear specimen $\left(r, h_{0}, \alpha\right)$ has been modified by FEM analysis for SHCC material to find a uniform shear stress distribution along the critical section (Shang and Zij1 2007 and Gideon and Zij1 2007). The shear behavior of SHCC was studied by Gideon and Zijl (2007). They observed, the two initial fine cracks that formed at notch upper and lower edge were arrested after which multiple diagonal cracks arose in the notch. The numerical simulation that was carried out by Gideon and Zijl (2007) confirmed the experimental observation. 
Two versions of the Iosipescu shear fixture and specimen were developed for composite materials (Ho et al. 1993) (Fig. 7). The original fixture and specimen (Fig. 7a) produced a very small region of uniform shear stress as a result of small depth of notched section and significant normal strains in the specimen test section. To overcome these deficiencies, a modified fixture and specimen were developed (Fig. 7b). The modified fixture can accommodate specimens of larger cross section height, larger fixture-to-specimen contact regions, and the innermost fixture-tospecimen contact zones were moved further away from the critical section. The uniform shear stress region increased but normal strains still exist in this section (Ho et al. 1993).

\section{Experimental Program:}

The experimental program aims, mainly, to determine the crack shear strength and the shear stress versus crack sliding of SHCC material, as well as it fracture energy of mode II, $G_{f_{s}}$. The dimensions of the specimens were $380 \times 140 \times 14.5$ $\mathrm{mm}^{3}$ with depth of the critical cross section $\left(h_{0}\right)$ of $25 \mathrm{~mm}$, angle of notch root of $(\alpha) 90^{\circ}$, and tip radius at notches equal to $(r) 2.5 \mathrm{~mm}$ (Fig. 8a). The specimen was designed by considering the comprehensive study was carried out by Shang and Zijl (2007) and Gideon and Zijl (2007) for finding the geometry of Iosipescu SHCC specimen that assures an uniform shear stress distribution. The fixture developed in the scope of the research carried out (Baghi 2015) is identical to the modified Iosipescu fixture. As shown in Fig. 8b, this fixture contacts entirely the horizontal top and bottom surfaces of the specimen, and it can also support specimens of other materials, thicknesses (up 70 $\mathrm{mm})$, and dimensions.

\section{Material Properties}

The SHCC was composed of a cementitious mortar reinforced with $2 \%$ of volume of short discrete polyvinyl alcohol (PVA) fibers. The SHCC mix was prepared based on a previous study (Esmaeeli et al. 2013). The dry ingredient materials (sand, cement, and fly ash) were firstly mixed. In the second step, the superplasticizer and a quarter of the water were combined and added to the dry ingredient materials. The rest of the water and the viscous modifier agent were then combined and introduced into the mix. Finally, PVA fibers were added to the mortar. Each Iosipescu specimen required about 1 liter of SHCC mix. After casting, these specimens were sealed by a plastic sheet and were kept in a room environment for 24 hours before de-molding. After de-molding, the specimens were transferred to the 
climate room and were cured under the constant conditions of $20^{\circ} \mathrm{C}$ temperature and $80 \%$ humidity up to the age of 28 days, in order to follow the curing procedure recommended in Esmaeeli et al. (2012). The average tensile stress at crack initiation and the average tensile strength of the SHCC was 2.35 and $3.4 \mathrm{MPa}$, respectively (Esmaeeli et al. 2013). More details on the preparation and testing the SHCC can be found elsewhere (Esmaeeli et al. 2012; Esmaeeli et al. 2013). The material properties of SHCC are presented in Table 1.

\section{Test setup and monitoring system}

The load was applied by using a servo closed loop control equipment, taking the signal read in the displacement transducer (LVDT) of the servo-actuator to control the test at a displacement rate of $0.005 \mathrm{~mm} / \mathrm{s}$. The load was recorded by using a load cell of $10 \mathrm{kN}$ capacity. The weight and the slight friction of the movable portion of fixture were taken into account on the evaluation of the strict load applied to the specimen. As shown in Fig. 8b, one LVDT was installed at the load cell to measure the displacement rate of the specimen, and another one was installed at the notched section (Fig. 9) to measure the sliding of the crack.

\section{Test results and discussion}

Ten specimens were tested. The average shear stress was determined by dividing the total applied load $(P)$ (measured by the load cell) by the area of the cross section between the two notches (Eq. 1):

$$
\tau_{\text {avg }}=\frac{P}{A}
$$

The envelope and the average curve corresponding to the average shear stress versus sliding relationship of the specimens are presented in Fig. 10a. Figure 10b shows the typical crack pattern of the specimens. Iosipescu specimens had similar failure mode and their shear stress-sliding curves denote the existence of three main phases. The first phase corresponds to the linear behavior up to a shear stress of about $0.8 \mathrm{MPa}(0.09 \mathrm{~mm})$ and formation of initial vertical cracks (Fig. 11a). These cracks were detected by spraying oil (WD-40) on the surface of the specimens. In the second phase, more micro cracks were formed up to peak load (Fig. 11b). When specimens reached their maximum load, the micro cracks were connected to each other and the load started decreasing (softening stage - Fig. 11c) up to end of the test (Fig. 10b). Based on the Fig. 11, for an average slip 2 times the average slip at peak load, the SHCC was still capable of supporting $50 \%$ of the average shear strength, which denotes the ductility of this composite material when subjected to shear deformations. 
By calculating the area under the curve of average shear stress versus sliding after crack initiation (Fig. 10a), the mode II fracture energy of the SHCC material was estimated about $1.4 \mathrm{~N} / \mathrm{mm}$, which corresponds to approximately $40 \%$ of its mode I fracture energy determined by direct tensile tests with notched specimens (Esmaeeli et al. 2013).

\section{Numerical Simulation:}

The two dimensional multi-directional fixed smeared crack model described in Sena-Cruz (2004), implemented in the FEM-based computer program FEMIX (Sena-Cruz et al. 2007), was used in the numerical simulations carried out in this work. To simulate the crack initiation and the fracture mode I propagation of SHCC, the tri-linear tensionsoftening diagram represented in Fig. 12a was adopted (Sena-Cruz 2004), which is defined by the parameters $\alpha_{i}$ and $\xi_{i}$, relating stress with strain at the transitions between the linear segments that compose this diagram. The ultimate crack strain, $\varepsilon_{n, u}^{c r}$, is defined as a function of the parameters $\alpha_{i}$ and $\xi_{i}$, the fracture energy, $G_{f}^{I}$, the tensile strength, $\sigma_{n, 1}^{c r}=f_{c t}$, and the crack bandwidth, $l_{b}$. More information about this diagram can be found in Sena-Cruz (2004) and Barros et al. (2013). The values of this diagram are indicated in Table 2. This table also includes the data necessary to define the shear-softening diagram that simulates the degradation of crack shear stress transfer after crack initiation (Ventura-Gouveia et al. 2008; Ventura-Gouveia 2011; Barros et al. 2013; Soltanzadeh et al. 2015) represented in Fig. $12 b$.

To simulate the fracture mode II modulus, $D_{I I}^{c r}$, a shear retention factor is used (Sena-Cruz 2004) (Eq. 2):

$$
D_{I I}^{c r}=\frac{\beta}{1-\beta} G_{c}
$$

where $G_{c}$ is the concrete elastic shear modulus and $\beta$ is the shear retention factor. The parameter $\beta$ is defined as a constant value or as a function of the current crack normal strain, $\varepsilon_{n}^{c r}$, and of the ultimate crack normal strain, $\varepsilon_{n, u}^{c r}$, as follows (Eq. 3),

$$
\beta=\left(1-\frac{\varepsilon_{n}^{c r}}{\varepsilon_{n, u}^{c r}}\right)^{p_{1}}
$$

when $P_{1}=1$ a linear decrease of $\beta$ with the increase of $\varepsilon_{n}^{c r}$ is assumed. Larger values of the exponent $P_{1}$ correspond to a more pronounced decrease of the $\beta$ parameter. 
In structures governed by flexural failure modes, this strategy leads to simulations with reasonable accuracy. Exceptions occur in structures that fail by the formation of a critical shear crack. To simulate accurately the deformational response and the crack pattern up to the failure of this type of structures, the adoption of a softening crack shear stress versus crack shear strain relationship is the strategy explored in the present work (Fig. 12b).

The crack shear stress increases linearly until the crack shear strength is reached, $\tau_{t, p}^{c r}$, (first branch of the shear crack diagram), followed by a decrease in the shear residual strength (softening branch). The diagram represented in Fig. $12 \mathrm{~b}$ is defined by Eq. 4:

$$
\tau_{t}^{c r}\left(\gamma_{t}^{c r}\right)=\left\{\begin{array}{lr}
D_{t, 1} \gamma_{t}^{c r} & 0<\gamma_{t}^{c r} \leq \gamma_{t, p}^{c r} \\
\tau_{t, p}^{c r}-\frac{\tau_{t, p}^{c r}}{\left(\gamma_{t, u}^{c r}-\gamma_{t, p}^{c r}\right)}\left(\gamma_{t}^{c r}-\gamma_{t, p}^{c r}\right) & \gamma_{t, p}^{c r}<\gamma_{t}^{c r} \leq \gamma_{t, u}^{c r} \\
0 & \gamma_{t}^{c r}>\gamma_{t, u}^{c r}
\end{array}\right.
$$

The initial shear fracture modulus, $D_{t, 1}^{c r}$, is defined by Eq. $2\left(D_{I I}^{c r}\right.$ is replaced by $D_{t, 1}^{c r}$ ) by assuming for $\beta$ a constant value in the range ]0,1[. The peak crack shear strain, $\gamma_{t, p}^{c r}$, is obtained using the crack shear strength (from the input data), $\tau_{t, p}^{c r}$, and the crack shear modulus (Eq. 5):

$$
\gamma_{t, p}^{c r}=\frac{\tau_{t, p}^{c r}}{D_{t, 1}^{c r}}
$$

The ultimate crack shear strain, $\gamma_{t, u}^{c r}$, depends on the crack shear strength, $\tau_{t, p}^{c r}$, on the shear fracture energy (mode II fracture energy), $G_{f, s}$, and on the crack bandwidth, $l_{b}$ (Eq. 6):

$$
\gamma_{t, u}^{c r}=\frac{2 G_{f, s}}{\tau_{t, p}^{c r} l_{b}}
$$

In the present approach it is assumed that the crack bandwidth, used to assure that the results are independent of the mesh refinement (Rots 1988). When the softening constitutive law represented in Fig. 12b is used to evaluate the fracture mode II softening modulus, $D_{I I}^{c r}$, its value depends on the branches defining the diagram. For this reason five shear crack statuses are proposed and their meaning is schematically represented in Fig. $12 \mathrm{~b}$.

The crack mode II modulus of the first linear branch of the diagram is defined by Eq. 2, the second linear softening branch is defined by Eq. 7: 


$$
D_{I I}^{c r}=D_{t, 2}^{c r}=-\frac{\tau_{t, p}^{c r}}{\gamma_{t, u}^{c r}-\gamma_{t, p}^{c r}}
$$

and the crack shear modulus of the unloading and reloading branches is obtained from Eq. 8:

$$
D_{I I}^{c r}=D_{t, 3-4}^{c r}=\frac{\tau_{t, \max }^{c r}}{\gamma_{t, \max }^{c r}}
$$

being $\gamma_{t, \text { max }}^{c r}$ and $\tau_{t, \text { max }}^{c r}$ the maximum crack shear strain already attained and the corresponding crack shear stress determined from the softening linear branch. Both components are stored to define the unloading/reloading branch (see Fig. 12b).

In free-sliding status $\left(\left|\gamma_{t}^{c r}\right|>\left|\gamma_{t, u}^{c r}\right|\right)$ the crack mode II stiffness modulus, $D_{I I}^{c r}=D_{t, 5}^{c r}$, is null. To avoid numerical instabilities in the calculation of the stiffness matrix and in the calculation of the internal forces, when the crack shear status is free-sliding, a residual value is assigned to this term.

A free-sliding status is assigned to the shear crack status when $\varepsilon_{n}^{c r}>\varepsilon_{n, u}^{c r}$. The physical meaning of the remaining variables of this constitutive model can be found elsewhere (Sena-Cruz 2004; Barros et al. 2013).

Figure 13 represents the finite element mesh used for the simulation of the specimen. The FE mesh was composed of 2015 nodes and 1920 serendipity 4 nodes plain stress elements with $2 \times 2$ Gauss-Legendre integration scheme. The adopted mesh refinement was adopted after some preliminary simulations in terms of assuring mesh objectivity of the results. This figure also shows the support and load conditions. The SHCC specimens can be considered as isotropic material in its plane due to random orientation nature of the short fibers (Shang and Zijl 2007). In fact, due to the relatively small thickness of the specimens from which the Iosipescu beam specimens are extracted, it is assumed fibers are oriented primarily in the plane. The force $P$ is the sum of all vertical forces in each node in contact with the movable part of the fixture. This force represents the uniform load imposed on the specimens and measured by the load cell in the experimental tests.

The inverse analysis process executed with simulation of the experimental test allowed determining the fracture energy of mode II and also shear retention factor. The experimental and the numerical relationship between average shear stress and the sliding of the crack at the notched plane for the tested specimens are compared in Fig 14a. The crack pattern of this specimen at the end of the analysis is represented in Fig 14b. The first crack appeared experimentally and numerically at a load of about $0.31 \mathrm{kN}$ and $0.4 \mathrm{kN}$, respectively. And softening stage started at a load of $1.3 \mathrm{kN}$ 
and $1.35 \mathrm{kN}$ for experimental and numerical, respectively. As it is shown in Fig 14, the numerical model is capable to capture, with acceptable accuracy, the shear behavior of the tested specimens.

\section{Parametric Study:}

The computer program, whose good predictive performance for the simulation of the behavior of the specimens under consideration was confirmed in the previous section, was adopted to execute a parametric study for the evaluation of the influence on the shear stress-sliding, and also on the crack pattern, of the following parameters: shear retention factor, fracture energy mode II, and crack shear strength that define the crack shear softening diagram. The advantages of using SHCC instead of plain cementitious material (PCM) was also analyzed. The finite element mesh, support, and load conditions were the same adopted in the numerical simulation of the specimen in previous section.

\section{Influence $\beta$ parameter defining the first branch of the $\tau_{t}^{c r}-\gamma_{t}^{c r}$ diagram}

In Fig. 15a, the influence of $\beta$ parameter on the average shear stress versus sliding response of the specimen is represented by adopting the following three values for this parameter: $0.01,0.15$, and 0.99 (all the remaining parameters were maintained the same). The first one is lower and the last one is higher than the value considered in the analysis of the specimen.

The results show that after formation of first shear crack at the notched plane at a sliding of about $0.10 \mathrm{~mm}$, the average shear capacity increases with $\beta$ for relatively small sliding values, as well as the brittleness of the response due to the increase of the stiffness of the pre-peak branch of the $\tau_{t}^{c r}-\gamma_{t}^{c r}$ diagram (Fig. 15b). By decreasing the $\beta$ parameter the crack shear deformation at crack shear strength, $\gamma_{t, p}^{c r}$, increases leading to a much higher ductile response up to the peak average shear stress, which has also increased.

\section{Shear retention factor versus softening diagram for modeling the crack shear behavior}

The relationship between the average shear stress and sliding for specimen when using the concept of shear retention factor, $\beta$, (Eq. (3) with $\mathrm{P}_{1}=3$ ) and adopting the $\tau_{t}^{c r}-\gamma_{t}^{c r}$ diagram is presented in Fig. 16a. Up to a sliding of about $0.10 \mathrm{~mm}$ (that corresponds to the formation of first shear crack at the notched plane) the responses are similar, but, above this sliding limit, the two approaches start diverging significantly. By using $\beta$ obtained according to Eq. (3), 
the load carrying capacity was much higher than the one predicted by using the $\tau_{t}^{c r}-\gamma_{t}^{c r}$ diagram. Then, the concept of the shear retention factor is not capable of simulating the decrease of the crack shear stress transfer $\left(\tau_{t}^{c r}\right)$ with the increase of the crack shear strain $\left(\gamma_{t}^{c r}\right)$. Figure $16 \mathrm{~b}$ compares the crack patterns of the specimen with $\beta$ factor and $\tau_{t}^{c r}-\gamma_{t}^{c r}$ diagram. As expected, the shear retention factor approach has predicted an incorrect failure mode and crack pattern.

\section{Influence of fracture energy mode II}

The average shear stress versus sliding for three different values of the shear fracture energy $\left(G_{f, s}\right), 0.1,0.5$ and 1.0 $\mathrm{N} / \mathrm{mm}$ (all the remaining parameters were maintained the same) are compared in Fig 17a, where the first value is lower and the last one is higher than the $G_{f, s}$ considered in the analysis of the experimentally tested specimen $(0.5 \mathrm{~N} / \mathrm{mm})$. The results show that the load carrying and sliding capacity increase with $G_{f, s}$, since the crack shear stress degradation in the softening stage is less pronounced with the increase of $G_{f, s}$ (Fig. 17b).

\section{Influence of crack shear strength}

Figure 18a compares the average shear stress versus sliding obtained for three different values of the crack shear strength $\left(\tau_{t, p}^{c r}\right), 0.1,1.0$ and 2.0 MPa (all the remaining parameters were maintained the same), the first one is lower and the last one is higher than the value considered in the analysis of the experimentally tested specimen (1.0 MPa). The obtained results show that the average shear strength increases with $\tau_{t, p}^{c r}$, since the entrance in the crack shear softening stage is postponed for later stages of the sliding process, $\tau_{t, p}^{c r}$ (Fig. 18b). Since the fracture energy mode II was the same in the three simulations, the post-peak response of the specimen is, however, as brittle as higher is $\tau_{t, p}^{c r}$ (Fig. 18b).

\section{Plain cementitious material versus SHCC}

Figure 19a compares the shear stress versus sliding relationship obtained when the specimen is made by a plain cementitious material (PCM) and a SHCC. The material properties of the PCM are presented in Table 3 (Baghi 2015). Apart the properties of these two materials, the remaining simulation conditions (geometry, loading and supports) 
were the same in both analyses. As expected, the specimen consisting of PCM failed at lower average shear strength than the specimen of SHCC. The PCM specimen had a brittle behavior, with an abrupt load decay just after peak load, while the SHCC specimen developed a pronounced nonlinear phase up to the average shear strength, followed by a relatively smooth softening response. The typical failure mode of PCM reported by Shang and Zijl (2007) and Gideon and zijl (2007) is presented in Fig. 19b, which was very well captured by numerical simulation (Fig. 19c). In fact, first cracks are formed near the notch tips (red circle in Fig. 19c), and propagated with an inclination of about $45^{\circ}$.

\section{Conclusion:}

The shear behavior of the SHCC was investigated by Iosipescu shear test method. The shear stress-sliding curves obtained in this test was characterized by three phases: 1) a first linear response that ends at an average shear stress of $0.8 \mathrm{MPa}$ at a sliding of $0.09 \mathrm{~mm}$; a second phase corresponding to the development of micro cracks with a continuous decrease of shear stiffness up to peak load (at an average shear strength of $3.9 \mathrm{MPa}$ and sliding of $0.5 \mathrm{~mm}$ ); and the third phase where a shear softening stage was occurred due to the degeneration of micro- in macro-cracks in the shear critical region; however, for an average slip 2 times the average slip at peak load the SHCC was still capable of supporting $50 \%$ of the average shear strength, which denotes the ductility of this composite material when subjected to shear deformations. By calculating the area under the curve of average shear stress versus sliding, the fracture energy mode II of SHCC material was estimated about $1.4 \mathrm{~N} / \mathrm{mm}$, which corresponds to $40 \%$ of its mode I fracture energy.

The capability of a FEM-based computer program to predict the behavior up to its failure of SHCC elements subjected to direct shear was investigated. From this study it was verified that the crack shear softening diagram available in the multi-directional fixed smeared crack model, implemented in the FEMIX computer program, allows simulating the shear behavior of the Iosipescu specimen. This has allowed the evaluation, from inverse analysis, the fracture parameters mode II of SHCC.

A parametric study was carried out: i) to study the influence of parameters that define the shear softening diagram on the shear stress-sliding response of SHCC specimens submitted to direct shear, ii) to illustrate the advantages of SHCC versus mortar when shear loading is governing the failure mode. It was verified that the shear stress of the specimens decrease by increasing the shear retention factor, $\beta$, due to the higher crack shear stress transfer, by using the concept of shear retention factor, $\beta$, for modeling the crack shear stress transfer, an abnormal high shear stress was estimated, 
with an incorrectly predicted failure mode, while adopting softening diagram, not only the response of the specimen, but also the failure mode and the crack pattern were correctly estimated. It was verified that load carrying and sliding

capacity of the specimen increase with $G_{f, s}$. The obtained results also showed by increasing $\tau_{t, p}^{c r}$ the average shear strength increased, since the entrance in the crack shear softening stage is postponed for later stages of the sliding process. The specimen consisting of plain cementitious material (PCM) failed at a lower shear stress than of the specimen with SHCC. The specimen with PCM had a brittle behavior, with an abrupt load decay just after peak load.

\section{ACKNOWLEDGMENTS}

The study presented in this paper is a part of the research project titled "PrePam -Pre-fabricated thin panels by using advanced materials for structural rehabilitation" with reference number of PTDC/ECM/114511/2009 provided by FCT (Fundação para a Ciência e a Tecnologia). The first author acknowledges the research grant provided by this project. The authors also thank the collaboration of the following companies: Sika for the sand and adhesive, Grace for the superplasticizers, Dow Chemical Co. for viscous modifying agents, and ENDESA Compostilla power station for the fly ash. 


\section{References:}

ASTM (American Society for Testing and Materials).(1993). "Standard Test Method for Shear Properties of Composite Materials by the V-Notched Beam Method." ASTM D 5379.

ASTM (American Society for Testing and Materials).(2000). "Standard Test Method for Short-Beam Strength of Polymer Matrix Composite Materials and Their Laminates." D 2344.

Baghi, H. (2015). The effectivness of SHCC-FRP panles of the shear resistance of RC beams. PhD Thesis, University of Minho.

Baghi, H., Barros, A.O.J., Rezazadeh, M., and Laranjeira, J. (2015). "Strengthening of Damaged Reinforced Concrete Beams with Hybrid 1 Composite Plates." Journal of Composites for Construction (ASCE), DOI: 10.1061/(ASCE)CC.1943-5614.0000601.

Ballatore, E., Carpinteri, A., Ferrara, G., and Melchiorri, G. (1990). "Mixed Mode Fracture Energy of Concrete." Engineering Fracture Mechanics, 35 (1): 145-157.

Banks-Sills, L., and Arcan, M. (1983). "An Edge Crack Mode II Fracture Specimen." Experimental Mechanics, 23 (3) $257-261$.

Barr, B., and Derradj, M. (1990). "Numerical Study of a Shear (Mode II) Type Test Specimen Geometry." Engineering Fracture Mechanics, 35 (1), 171-180.

Barros, J. A. O., Baghi, H., Dias, S.J.E., and Ventura-Gouveia. A. (2013). "A FEM-based model to predict the behaviour of RC beams shear strengthened according to the NSM technique." Engineering Structures, 56, $1192-1206$.

Boulifa, R., M. Samami, M.L., and Benhassine, M. T. (2013). "A New Technique for Studying the Behaviour of Concrete in Shear." Journal of King Saud University, 25(2), 149-159.

Collins, M. P., and Mitchell, D. (1991). Prestressed concrete structures, New Jersey: Prentice-Hall.

Derradj, M., and Kaci, S. (2008). "Numerical Study of Compact Shear (Mode II) Type Test Specimen Geometry." Materials and Structures, 41(7), 1203-1210.

Esmaeel Esmaeeli, Barros, A.O.J., José Sena-Cruz, Fasan, L., Prizzi, F.R.L., Melo, J., and Varum, H. (2015). "Retrofitting of interior RC beam-column joints using CFRP strengthened SHCC: Cast-in-place solution." Composite Structures, 122, 456-467. 
Esmaeeli, E., Barros, A.O.J., and Mastali, M. (2012). Effects of curing conditions on crack bridging response of PVA reinforced cementitious matrix. 8th RILEM international symposium on fibre reinforced concrete: challenges and opportunities (BEFIB2012), University of Minho, Guimaraes, Portugal.

Esmaeeli, E., Manning, E., and Barros, A.O.J. (2013). "Strain hardening fibre reinforced cement composites for the flexural strengthening of masonry elements of ancient structures." Construction and Building Materials, 38, 1010-1021.

Gideon, P.A.G., Zijl, V. (2007). "Improved mechanical performance: Shear behaviour of strain-hardening cementbased composites (SHCC)." Cement and Concrete Research, 37(8), 1241-1247.

Ho, H., Tsai, M.Y., Morton, J., and Farley, G.L. (1993). "Numerical analysis of the Iosipescu specimen for composite materials." Composites Science and Technology, 46(2), 115-128.

Iosipescu, N. (1967). "New accurate method for single shear testing of metals." Journal of Materials, 2(3), 537-566.

Krishnan, A., and Xu, L.R. (2009). Stress Distribution on the Interfacial Shear Strength Measurements. SEM Annual Conference, Albuquerque New Mexico USA.

Morton, J., Ho, H., Tsai, M.Y., and Farley, G.L., (1992). "An evaluation of the Iosipescu specimen for composite materials shear property measurement." Journal of Composite materials, 26(5), 708-750.

Odegrad, G., and Kumosa, M., (2000). "Determination of shear strength of unidirectional composite materials with the Iosipescu and $10^{\circ}$ off-axis shear tests." Composites Science and Technology, 60 (16), 2917-2943.

Ohno, K. (1957). "Shear Tests of Reinforced Concrete Beam by Special Type of Loading." Transactions of the Architectural institute of Japan, 581-584.

Parra-Montesinos, G., and Wight, J.K. (2000). "Seismic response of exterior RC column-to steel beam connections." Journal of Structural Engineering (ASCE), 126 (10), 1113-1121.

Reinhardt, H. W., Ozbolt, J., Xu, S., and Dinku, A. (1997). "Shear of Structural Concrete Members and Pure Mode II Testing." Advanced Cement Based Materials, 5 (3), 75-85.

Rots, J. G. (1988). Computational modeling of concrete fracture. PhD Thesis, Delft University of Technology.

Sena-Cruz, J. M. (2004). Strengthening of concrete structures with near-surface mounted CFRP laminate strips. PhD Thesis, University of Minho. 
Sena-Cruz, J. M., Barros, J.A.O., Azevedo, A.F.M., and Ventura-Gouveia, A. (2007). Numerical simulation of the nonlinear behavior of RC beams strengthened with NSM CFRP strips. CMNE/CILAMCE Congress, FEUP, Porto, Portugal.

Shang, Q., and Zijl, G.V. (2007). "Characterising the Shear Behaviour of Strain-Hardening Fiber-Reinforced CementBased Composites." Journal of the South African Institution of Civil Engineering, 49 (2), 16-23.

Soltanzadeh, F., J. A. O. Barros, and R. F. C. Santos. "High performance fiber reinforced concrete for the shear reinforcement: Experimental and numerical research." Construction and Building Materials 77 (2015): 94109.

Swartz, S. E., Lu, L.W. Tang, L.D. and Refai, T.M.E. (1988). "Mode II Fracture-Parameter Estimates for Concrete from Beam Specimens." ExperimentaI Mechanics, 28(2), 146-153.

Ventura-Gouveia, A. (2011). Constitutive models for the material nonlinear analysis of concrete structures including time-dependent effects. PhD Thesis, University of Minho.

Ventura-Gouveia, A., Barros, J., Azevedo, A., and Sena-Cruz, J. (2008). Multi-fixed smeared 3d crack model to simulate the behavior of fiber reinforced concrete structures. CCC 2008 - Challenges for Civil Construction. Porto, Portugal.

Xavier, J. C., Garrido, N.M., Oliveira, M., Morais, J.L., Camanho, P.P., and Pierron, F. (2004). "A comparison between the Iosipescu and off-axis shear test methods for the characterization of Pinus Pinaster Ait." Composites part A: applied science and manufacturing, 35(7), 827-840. 


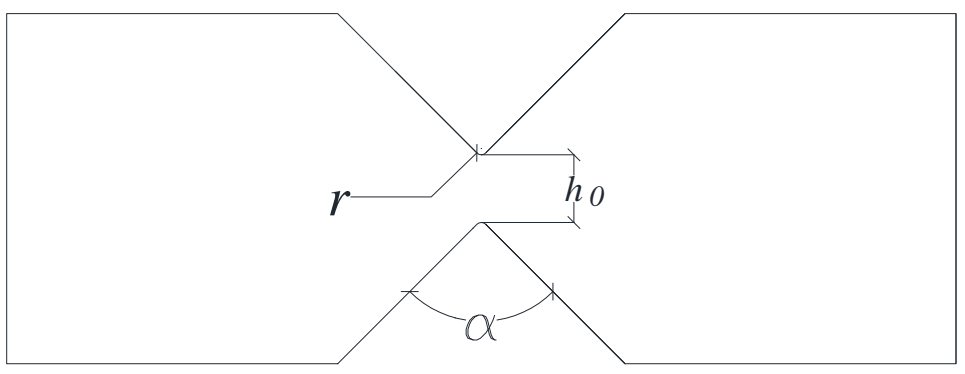

Fig. 1 - Geometry parameters of Iosipescu shear test 


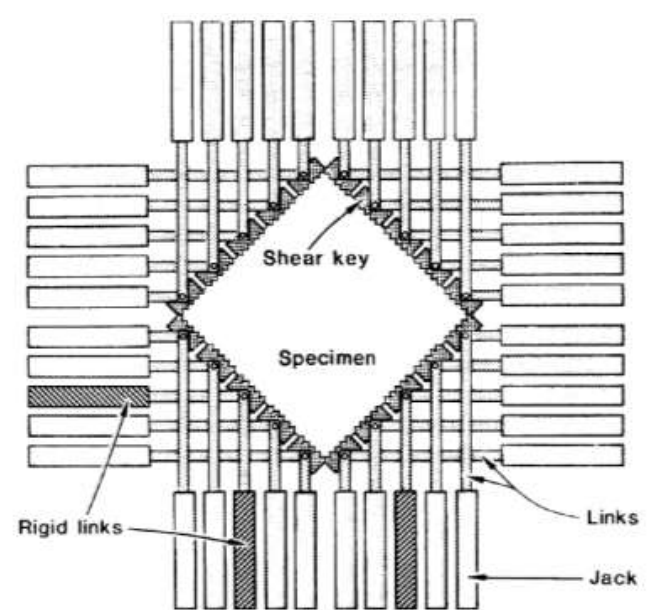

a) Pure shear test

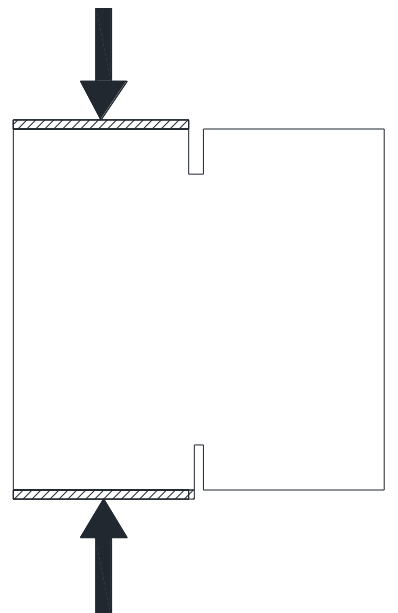

b) Double edge notched compression

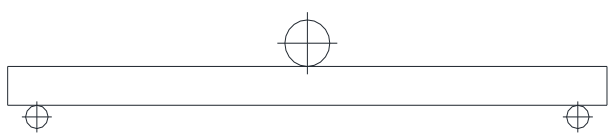

c) short beam shear test

Fig. 2 - Different mode II test setups: a) Pure shear panel test; b) Double-Edge Notched compression; c) short beam shear test 

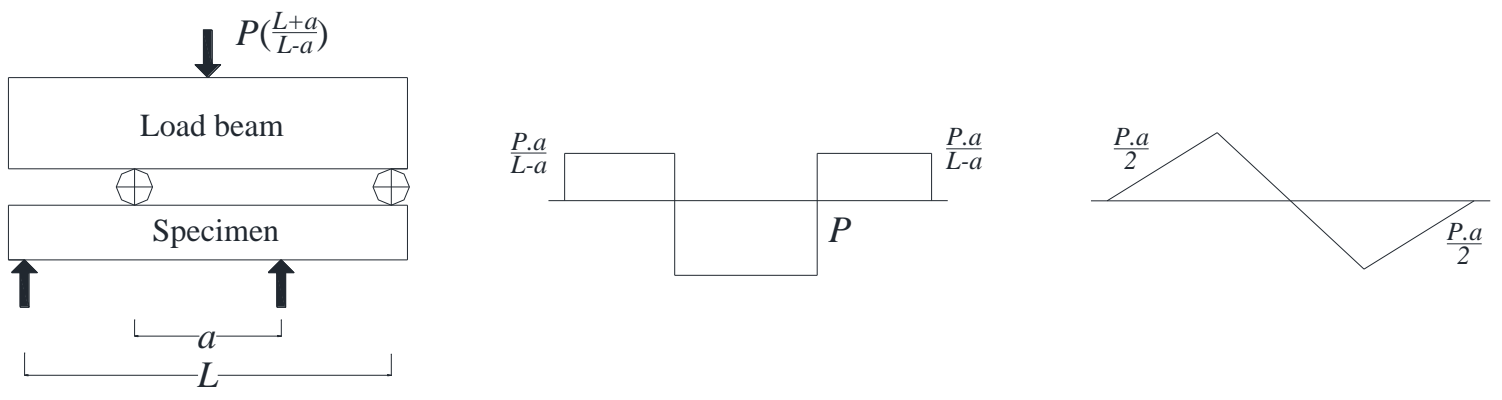

a) concept of Ohno shear beam test

b) shear force diagram

c) bending moment diagram

Fig. 3 - Ohno shear beam test: a) test setup; b) shear force diagram; c) bending moment diagram 


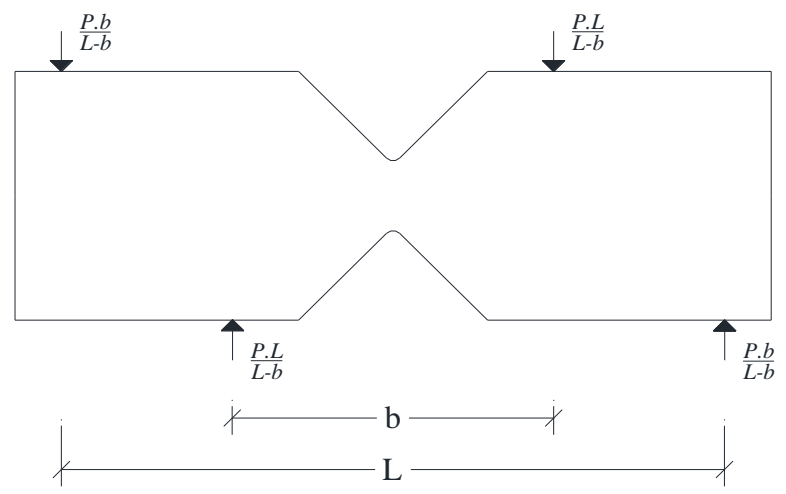

a) Iosipescu specimen

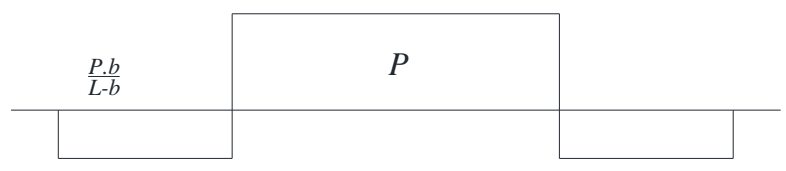

b) shear force diagram

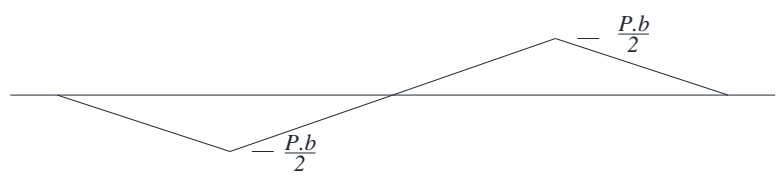

c) bending moment diagram

Fig. 4 - Shear force and bending moment diagrams in Iosipescu test 


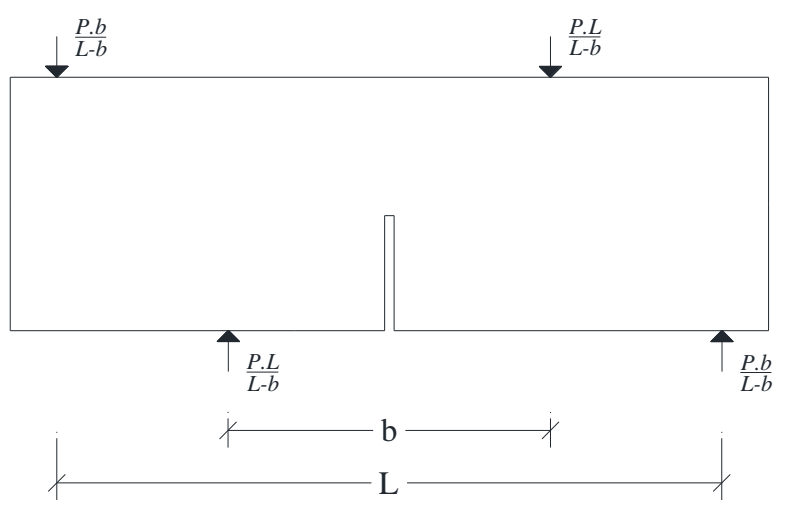

Fig. 5 - Single notch specimen 


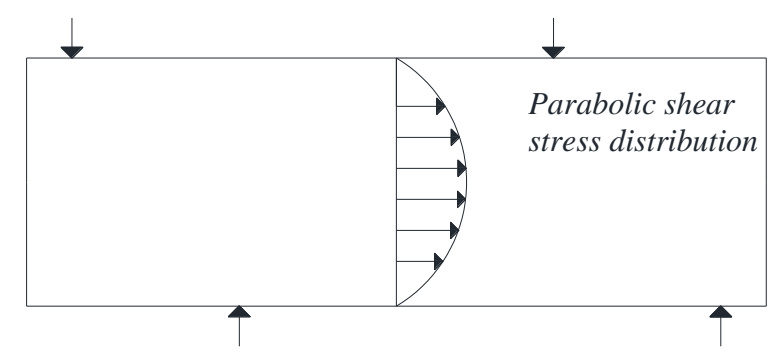

a) Ohno shear beam test

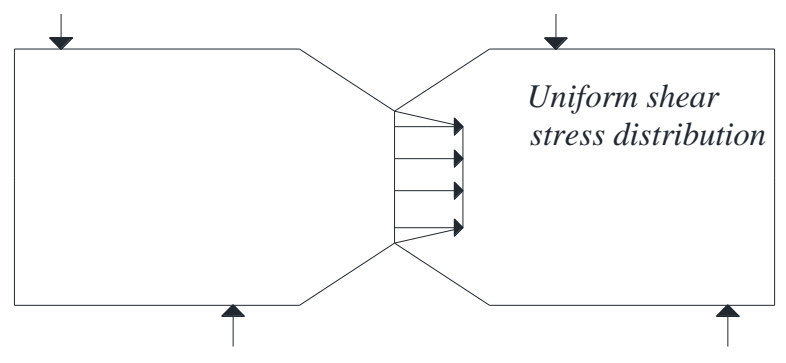

(b) Iosipescu shear test

Fig. 6 - Shear stress distribution on the critical section for the specimen a) Ohno, and b) Iosipescu 

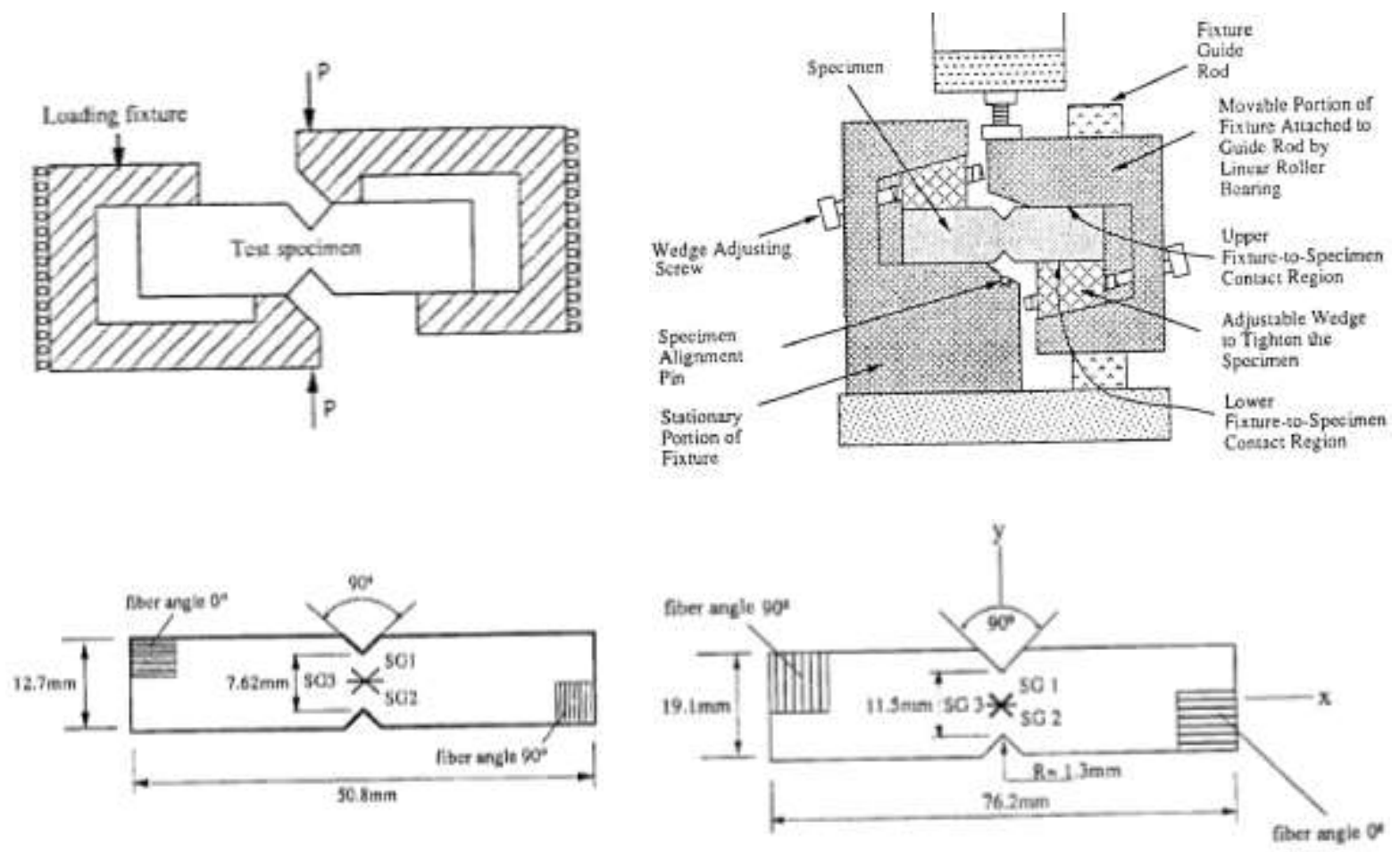

a) Original Iosipescu Fixture and specimen

b) Modified Iosipescu Fixture and specimen

Fig. 7 - Developed Iosipescu fixtures and specimens (Ho et al. 1993) 


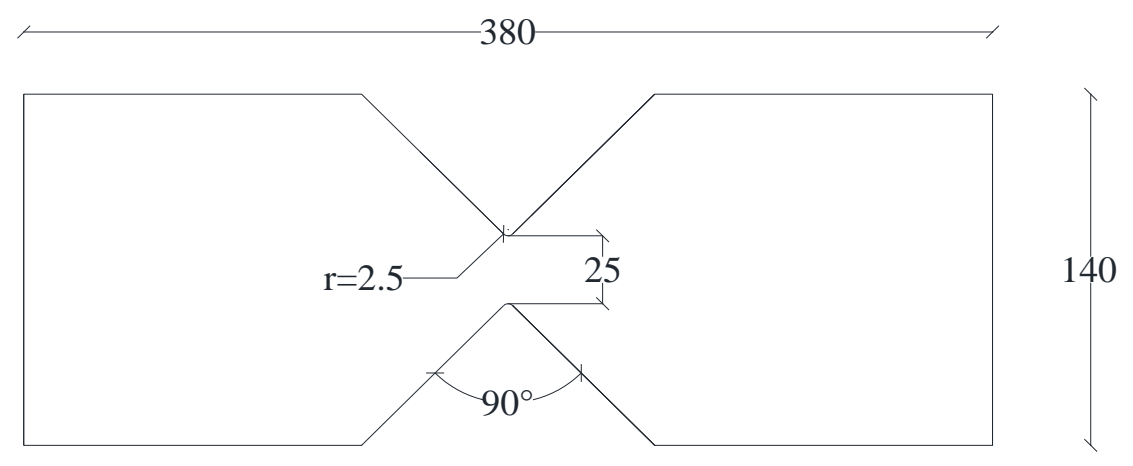

a) Iosipescu specimen

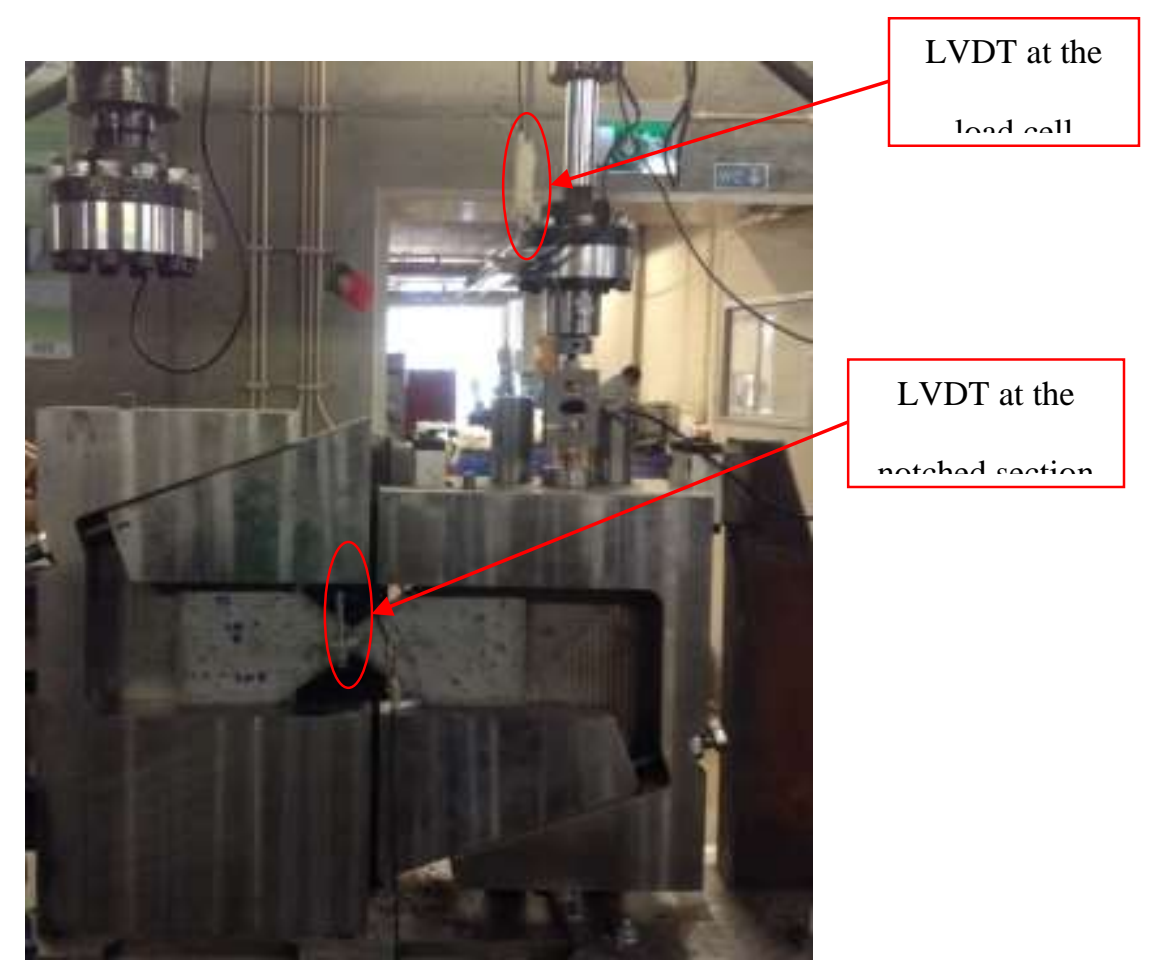

b) Fixture and position of the load cell and LVDTs

Fig. 8 - a) Adopted Iosipescu specimen; b) Iosipescu fixture developed at the University of Minho 

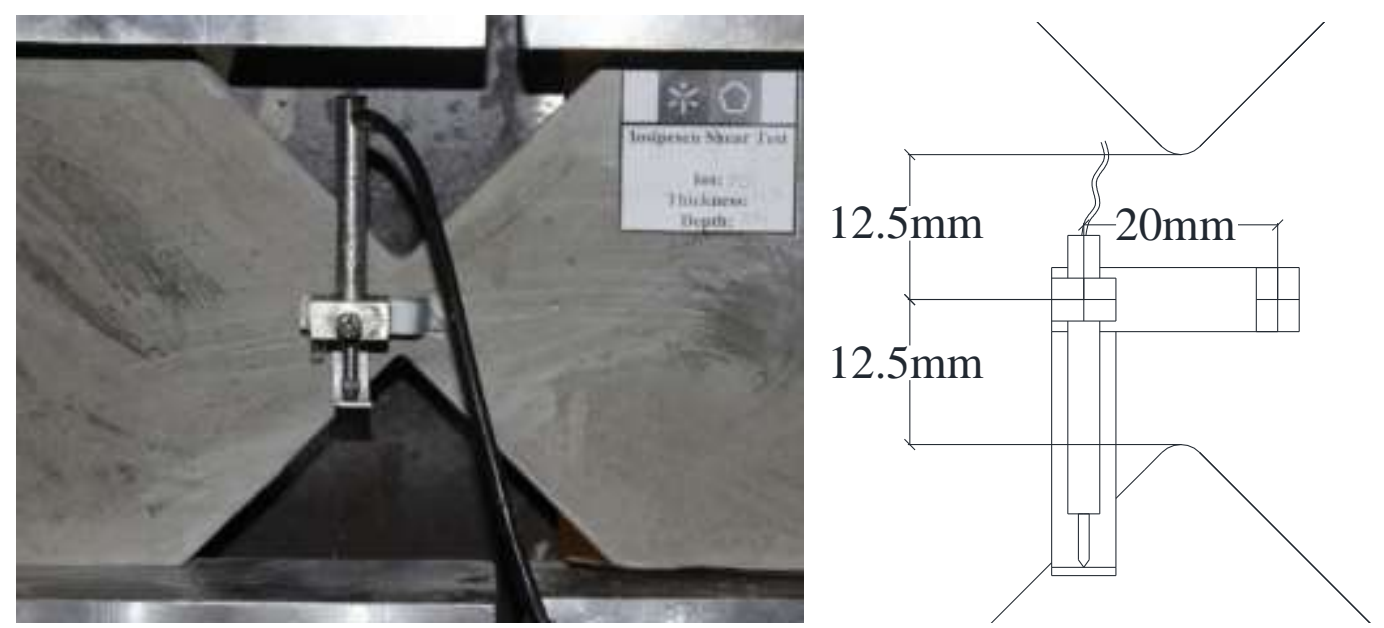

Fig. 9 - The position of the LVDT to measure the sliding of the shear crack formed in the notched section 


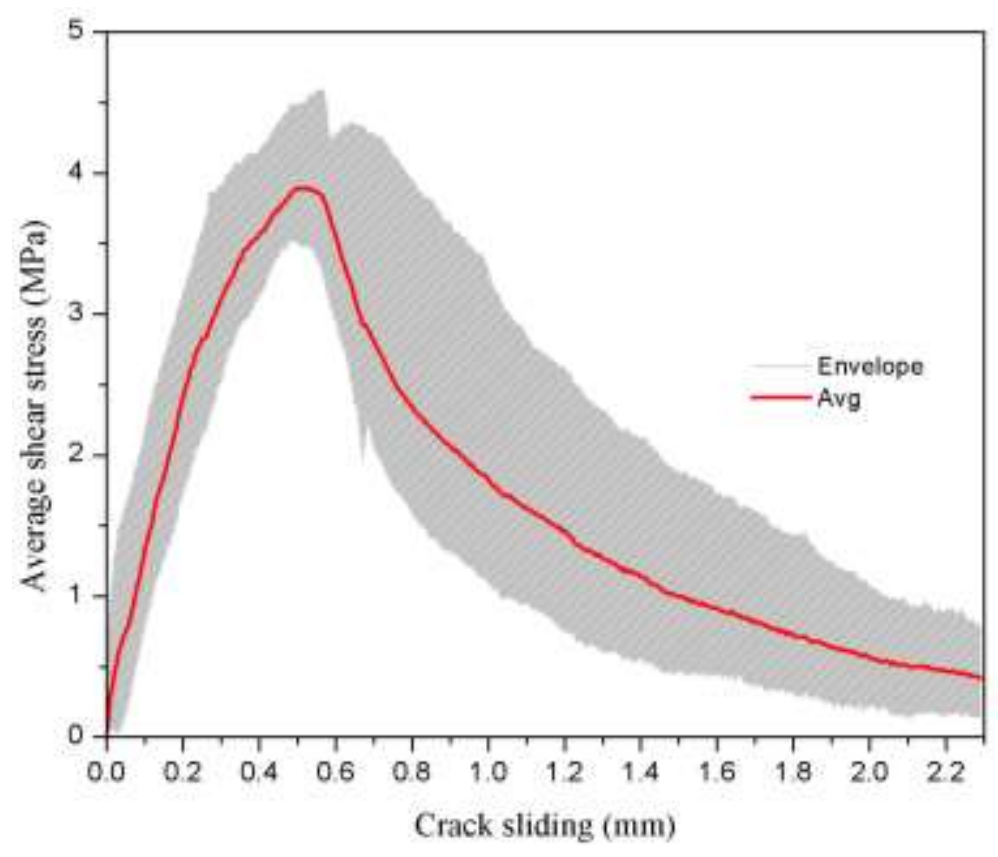

a)

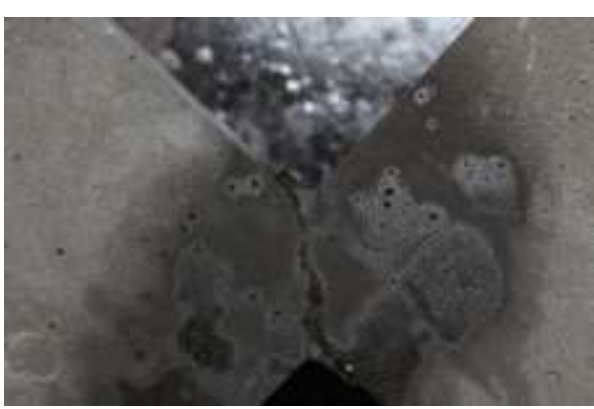

b)

Fig. 10 - a) The envelope and average stress versus crack sliding; b) Typical crack pattern in the tested Iosipescu specimens 

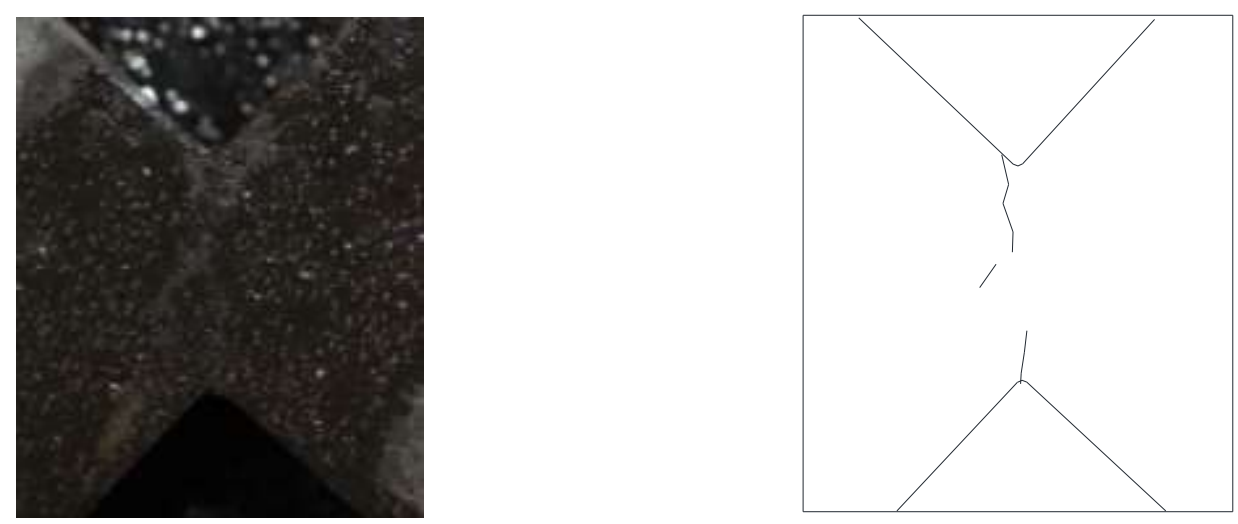

a) Crack pattern in the first phase (linear pre-peak up to a slide of around $0.09 \mathrm{~mm}$ )
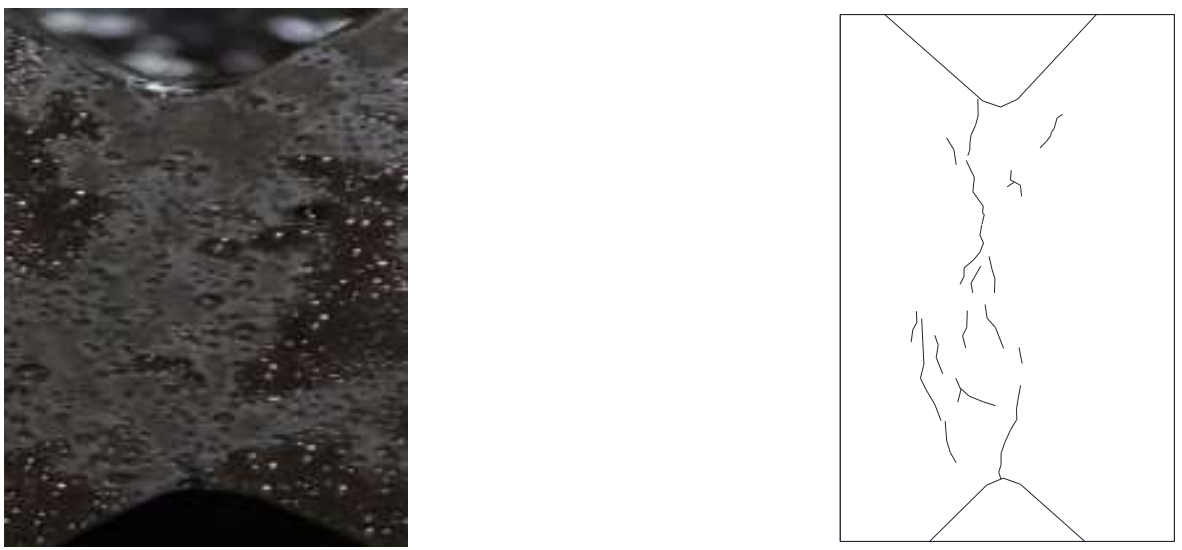

b) Crack pattern in the second phase (nonlinear pre-peak)
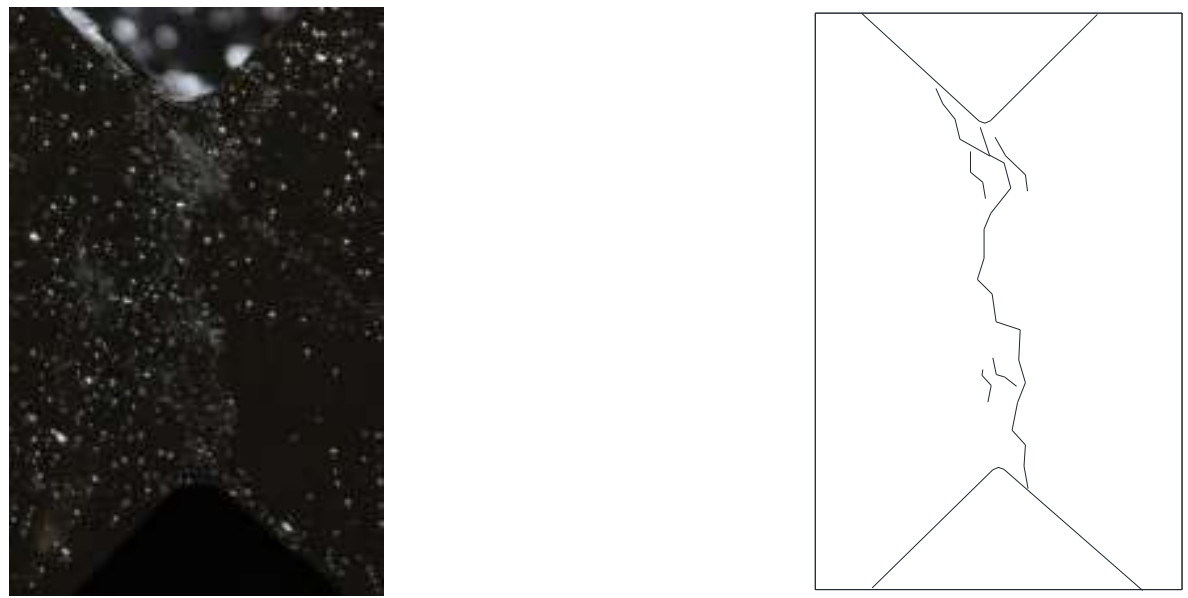

c) Crack pattern in shear softening (nonlinear post-peak)

Fig. 11 - Representative crack patterns in the relevant stages of a tested specimen 


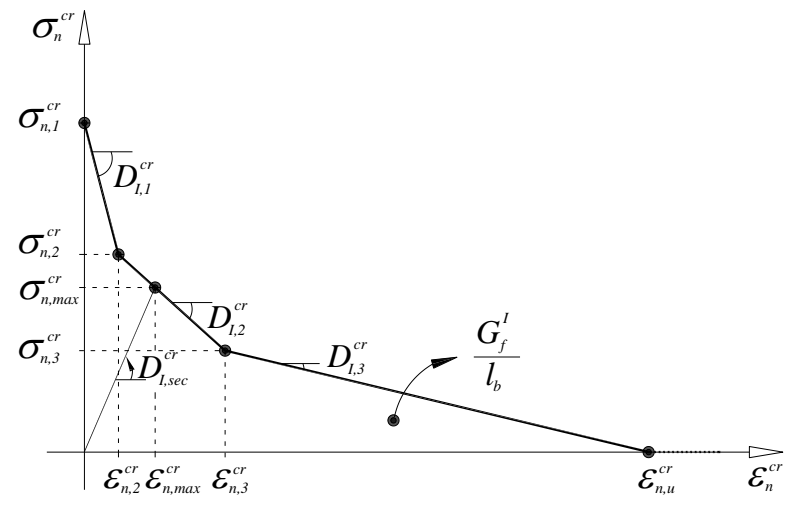

a)

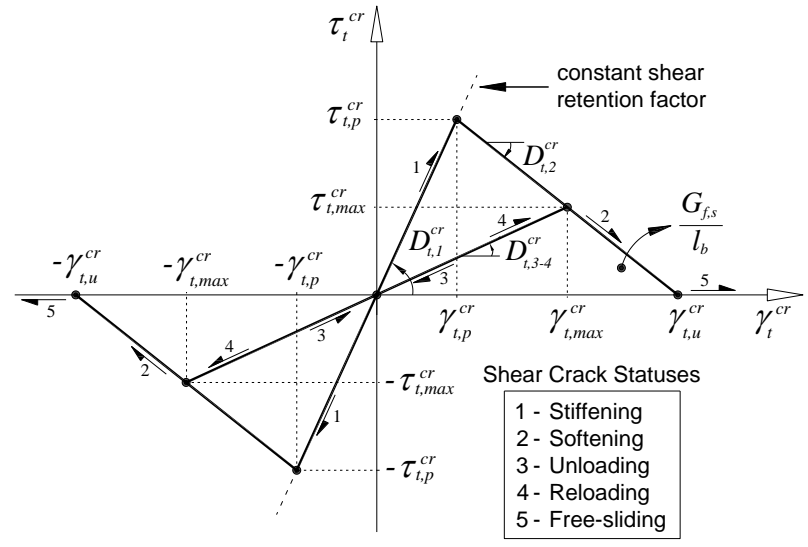

b)

Fig. 12 - a) Tri-linear stress-strain diagram to simulate the fracture mode I crack propagation $\left(\sigma_{n, 2}^{c r}=\alpha_{1} \sigma_{n, 1}^{c r}\right.$, $\left.\sigma_{n, 3}^{c r}=\alpha_{2} \sigma_{n, l}^{c r}, \varepsilon_{n, 2}^{c r}=\xi_{1} \varepsilon_{n, u}^{c r}, \varepsilon_{n, 3}^{c r}=\xi_{2} \varepsilon_{n, u}^{c r}\right)$; b) Diagram to simulate the relationship between the crack shear stress and crack shear strain component, and possible shear crack statuses 


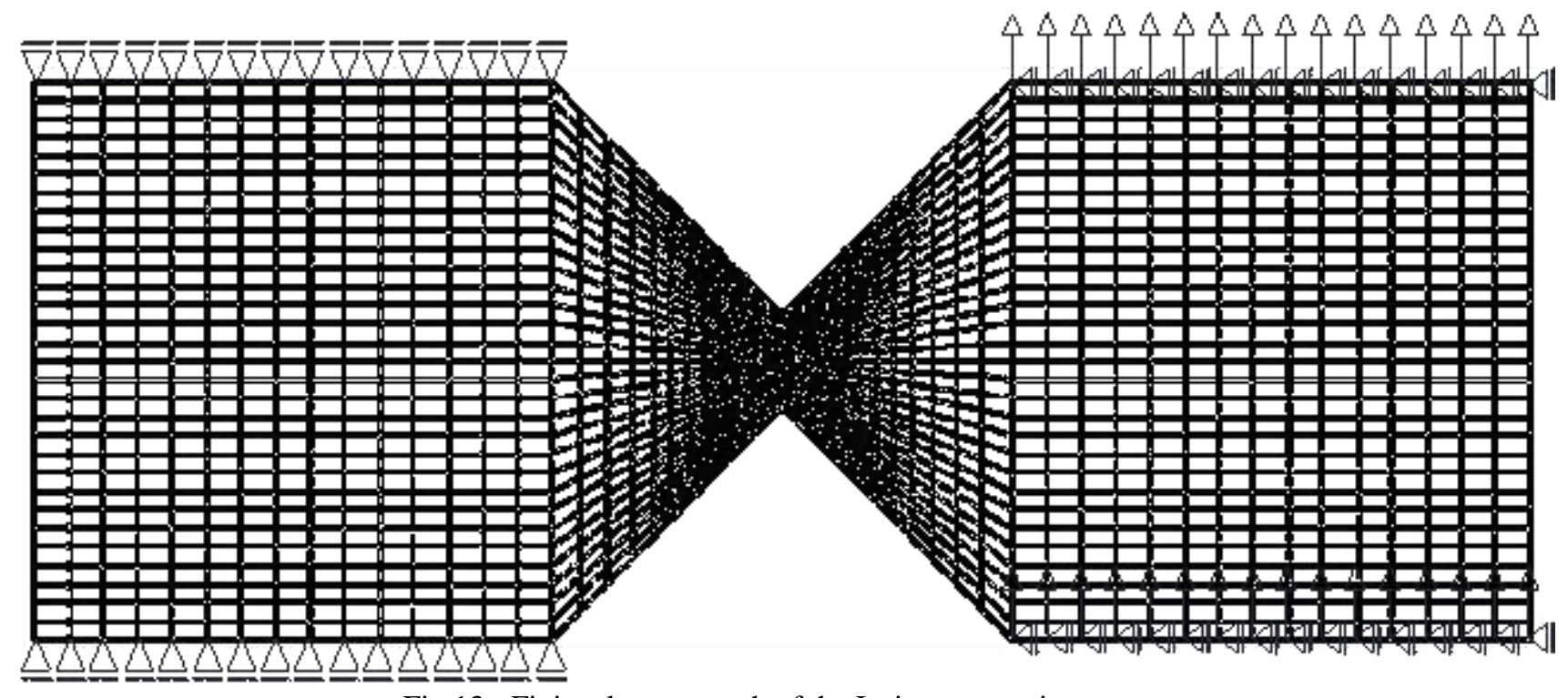

Fig 13 - Finite element mesh of the Iosipescu specimen 


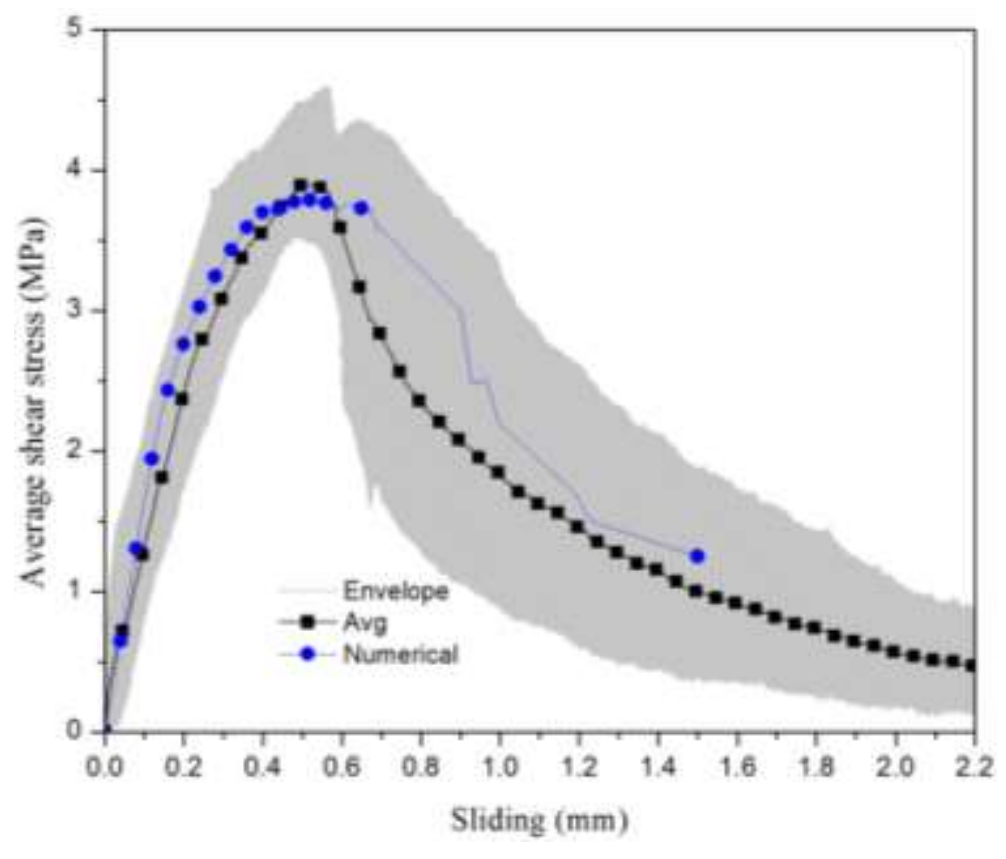

a)

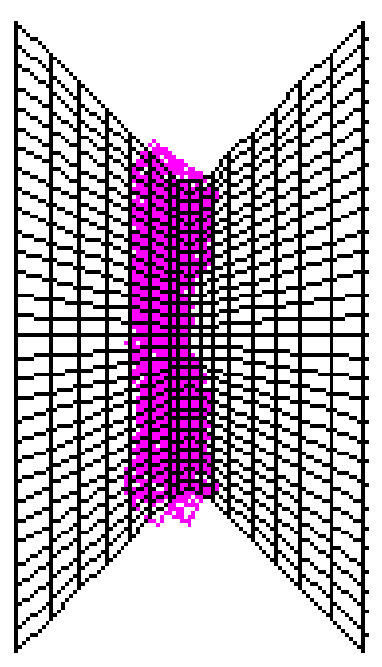

b)

Fig. 14 - a) Comparison between experimental and numerical average shear stress versus sliding relationship; b) Crack pattern of the specimens 


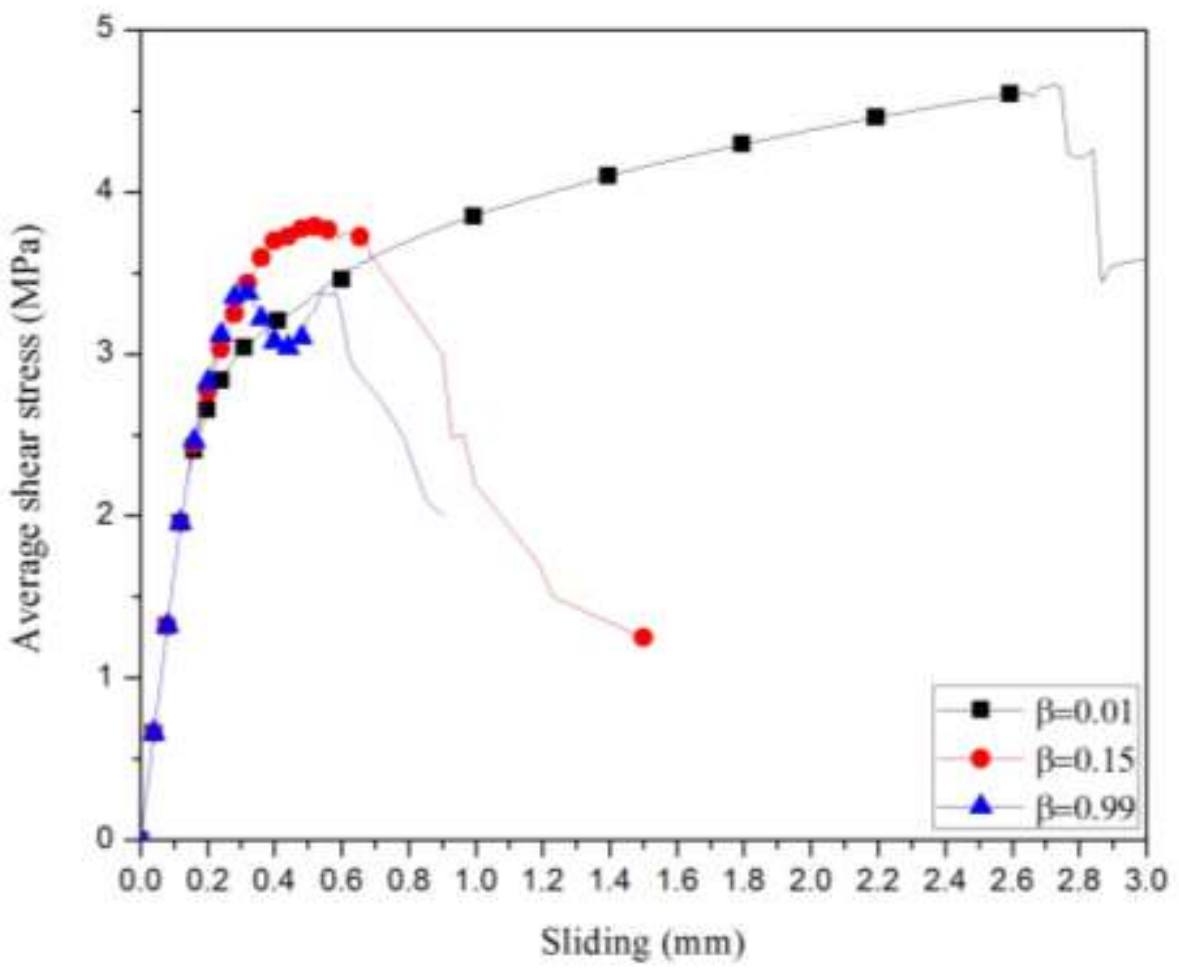

a) shear stress-sliding relationship 

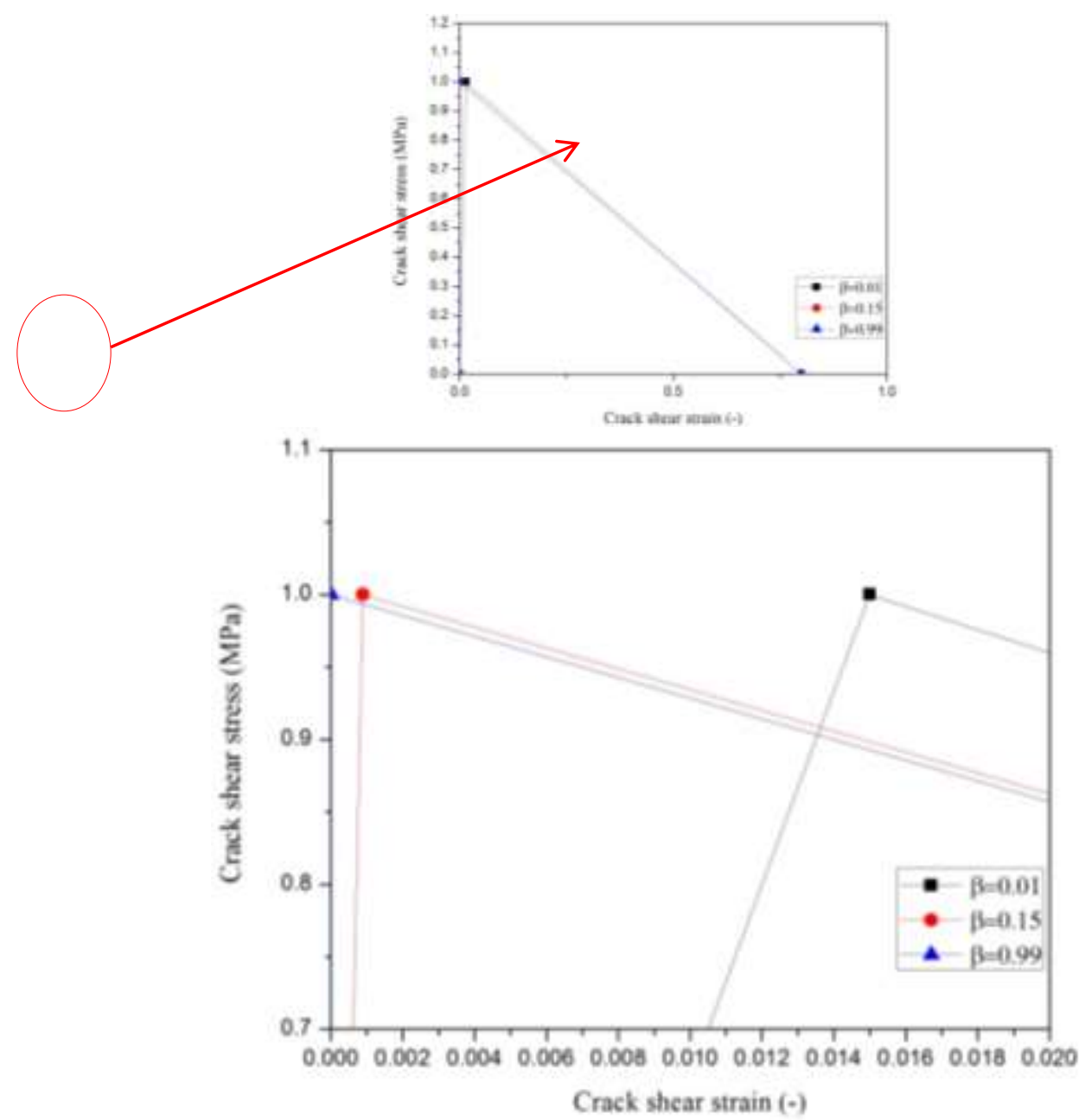

b) crack shear stress crack shear strain diagram

Fig. 15 - a) Influence of shear retention factor on average shear stress-sliding relationship; b) The crack shear stresscrack shear strain diagram for the $\beta$ equal to $0.01,0.15$, and 0.99 


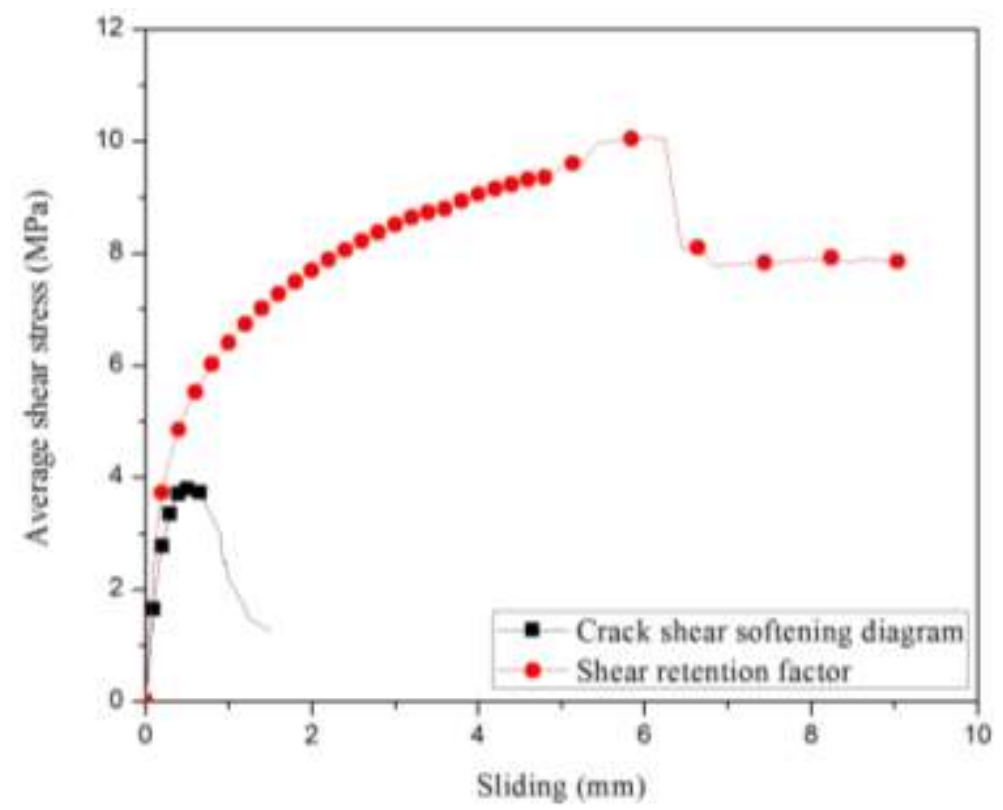

a) shear stress-sliding relationship

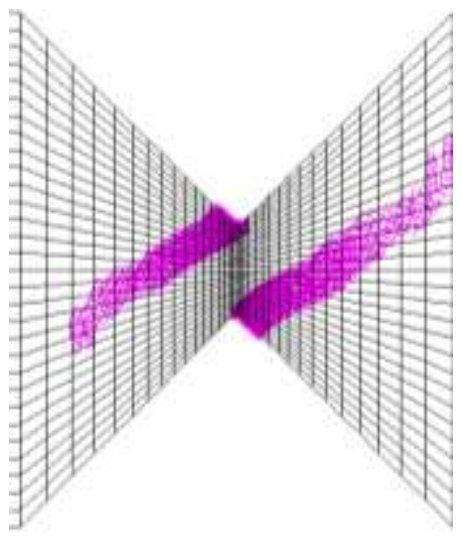

b) shear retention factor $P_{1}=3$

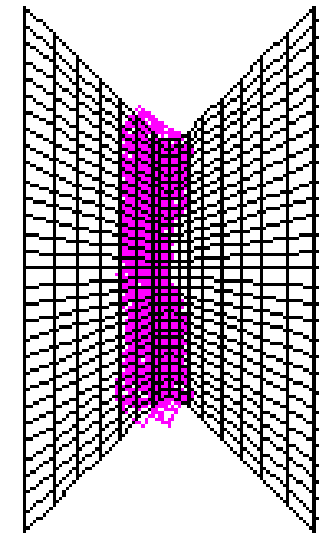

c) shear softening ( $\beta=0.15$ )

Fig. 16 - Influence of using the crack shear softening diagram versus shear retention factor with $P_{l}=3$ on the average shear stress-sliding relationship and crack pattern 


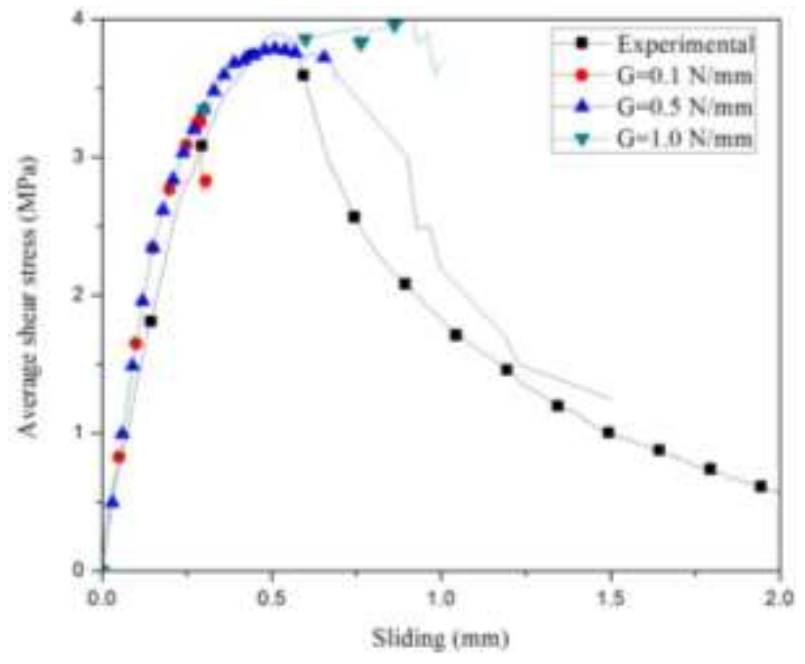

a) shear stress-sliding relationship

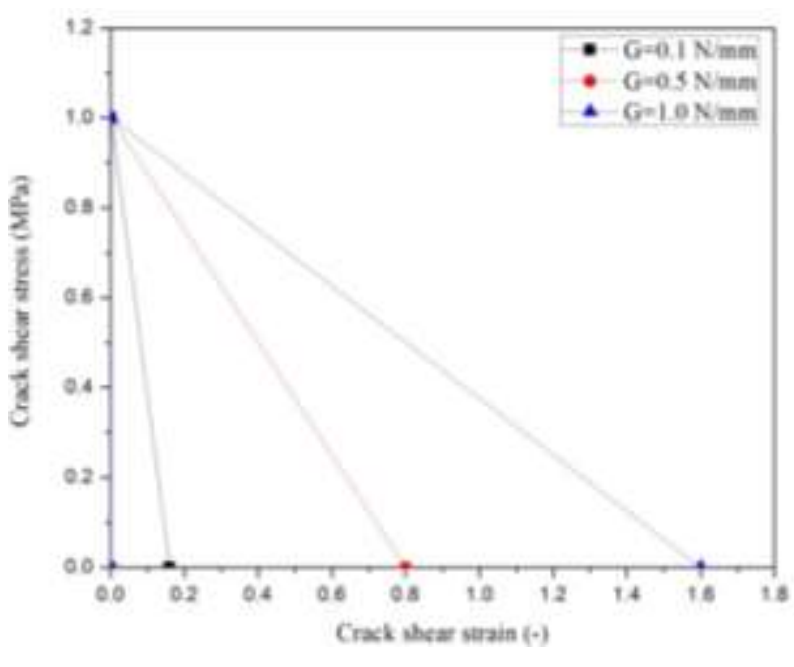

b) crack shear stress crack shear strain diagram

Fig. 17 - a) Influence of the fracture energy mode II on average shear stress-sliding relationship; b) The crack shear stress-crack shear strain diagram for the fracture energy mode II equal to $0.1,0.5$, and $1.0 \mathrm{~N} / \mathrm{mm}$ 


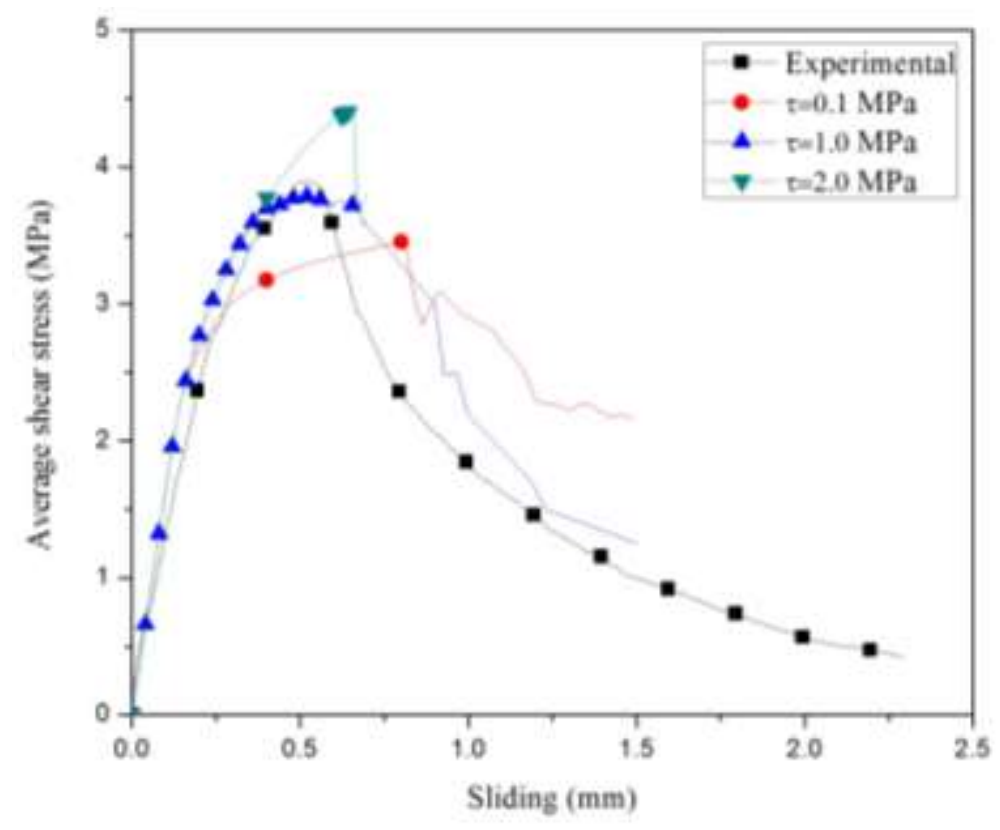

a) shear stress-sliding relationship

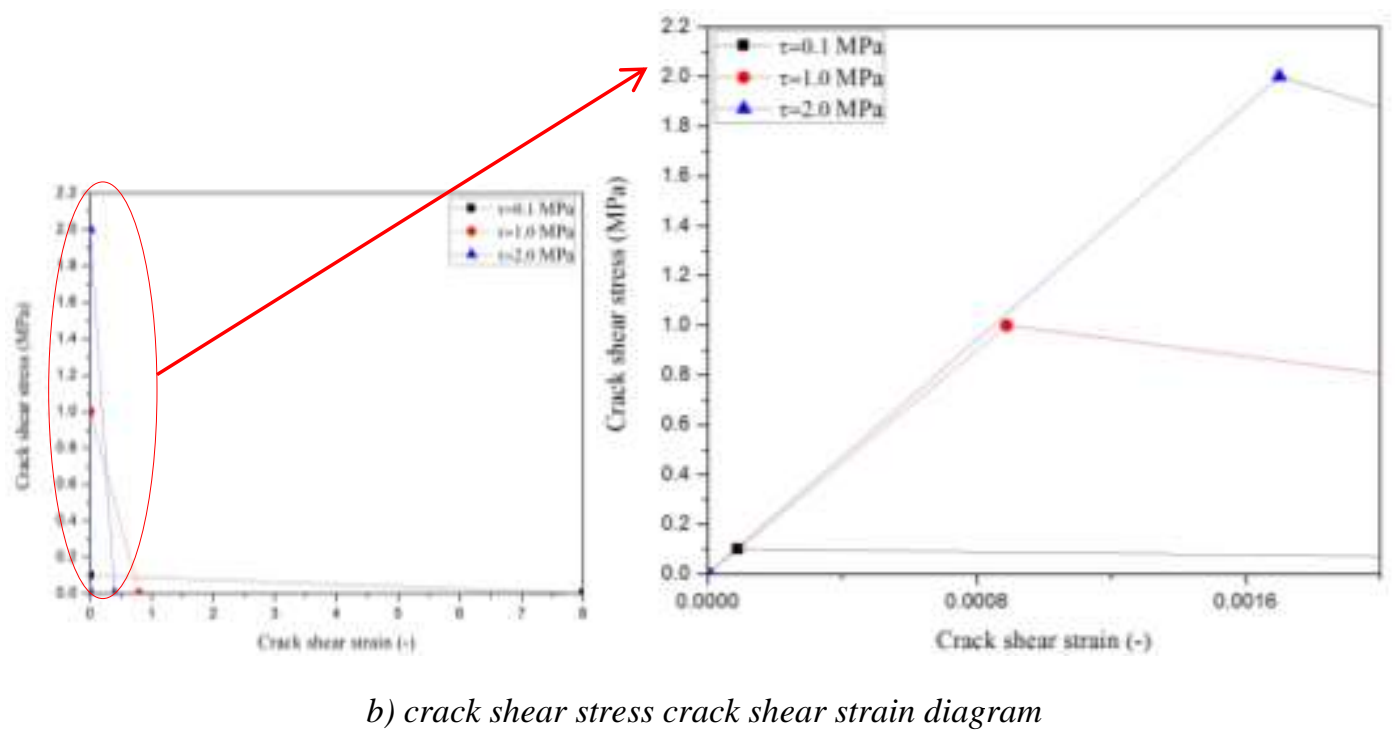

Fig. 18 - a) Influence of crack shear strength on average shear stress-sliding relationship; b) The crack shear stresscrack shear strain diagram for the crack shear strength equal to $0.1,1.0$, and $2.0 \mathrm{MPa}$ 


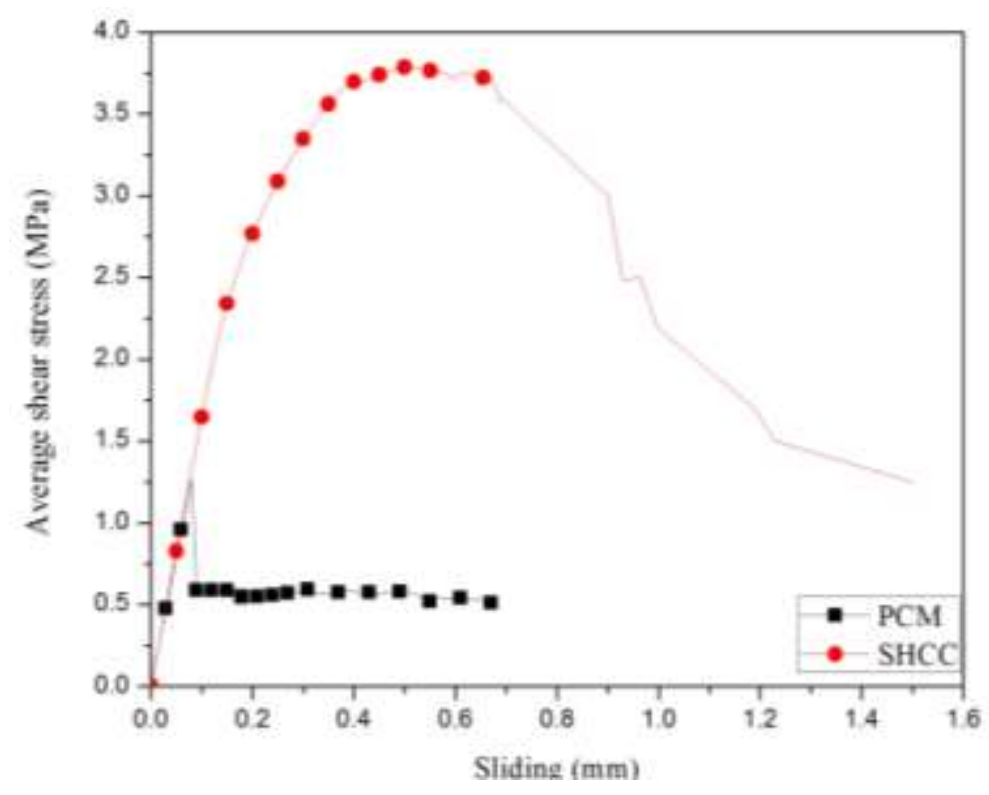

a) shear stress-sliding relationship

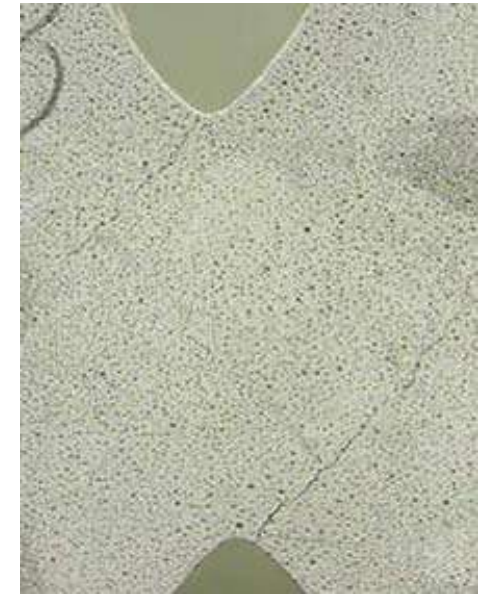

b) final crack pattern of PCM

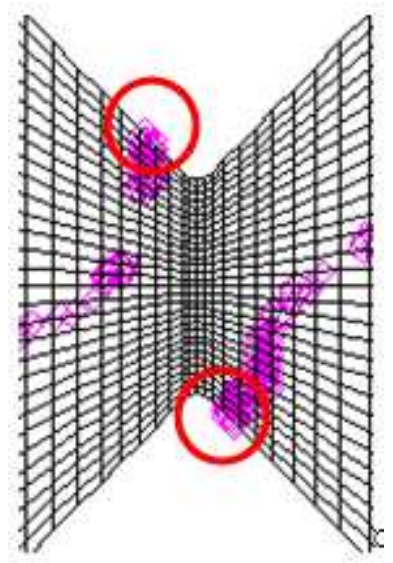

c) crack pattern of the PCM

Fig. 19 - Shear response and crack pattern of a specimen made by SHCC and Plain Cementitious Material (PCM) 


\section{List of table captions}

Table 1 - Values of the properties of SHCC materials

Table 2 - Values of the parameters of the SHCC constitutive model

Table 3 - Values of the parameters of the constitutive model for the PCM 
Table 1 - Values of the properties of SHCC materials

\begin{tabular}{lccccc}
\hline \multirow{2}{*}{ SHCC } & $\begin{array}{c}\text { Tensile stress at } \\
\text { crack initiation }\end{array}$ & Tensile strength & $\begin{array}{c}\text { Tensile strain at } \\
\text { tensile strength }\end{array}$ & $\begin{array}{c}\text { Compressive } \\
\text { strength }\end{array}$ & $\begin{array}{c}\text { Young's } \\
\text { modulus }\end{array}$ \\
\cline { 2 - 6 } & $2.35 \mathrm{MPa}$ & $3.4 \mathrm{MPa}$ & $1.3 \%$ & $31.6 \mathrm{MPa}$ & $18.4 \mathrm{GPa}$ \\
\hline
\end{tabular}


Table 2 - Values of the parameters of the SHCC constitutive model

\begin{tabular}{|c|c|c|c|c|c|c|c|c|c|c|c|}
\hline$v_{c}$ & $\begin{array}{c}E_{c} \\
\left(N / \mathrm{mm}^{2}\right)\end{array}$ & $\begin{array}{c}f_{c} \\
\left(N / \mathrm{mm}^{2}\right)\end{array}$ & $\begin{array}{c}f_{c t} \\
\left(N / \mathrm{mm}^{2}\right)\end{array}$ & $\begin{array}{c}G_{f} \\
(N / \mathrm{mm})\end{array}$ & $\xi_{1}$ & $\alpha_{1}$ & $\xi_{2}$ & $\alpha_{2}$ & $\begin{array}{c}\tau_{t, p}^{c r} \\
\left(N / m m^{2}\right)\end{array}$ & $\begin{array}{c}G_{f, s} \\
(N / m m)\end{array}$ & $\beta$ \\
\hline 0.10 & 14000 & 31.60 & 2.35 & 3.5 & 0.11 & 1.27 & 0.54 & 0.11 & 1.0 & 0.5 & 0.15 \\
\hline
\end{tabular}


1

Table 3 - Values of the parameters of the constitutive model for the PCM

\begin{tabular}{|c|c|c|c|c|c|c|c|c|c|c|c|}
\hline \multirow{2}{*}{$v_{c}$} & $\begin{array}{c}E_{c} \\
\left(N / \mathrm{mm}^{2}\right)\end{array}$ & $f_{c}$ & $f_{c t}$ & $G_{f}$ & $\xi_{1}$ & $\alpha_{1}$ & $\xi_{2}$ & $\alpha_{2}$ & $\tau_{t, p}$ & $G_{f, s}$ & $\beta$ \\
\hline 0.10 & 14000 & 31.60 & 1.8 & 0.08 & 0.005 & 0.3 & 0.1 & 0.3 & 1.0 & 0.045 & 0.60 \\
\hline
\end{tabular}

2

3

4 